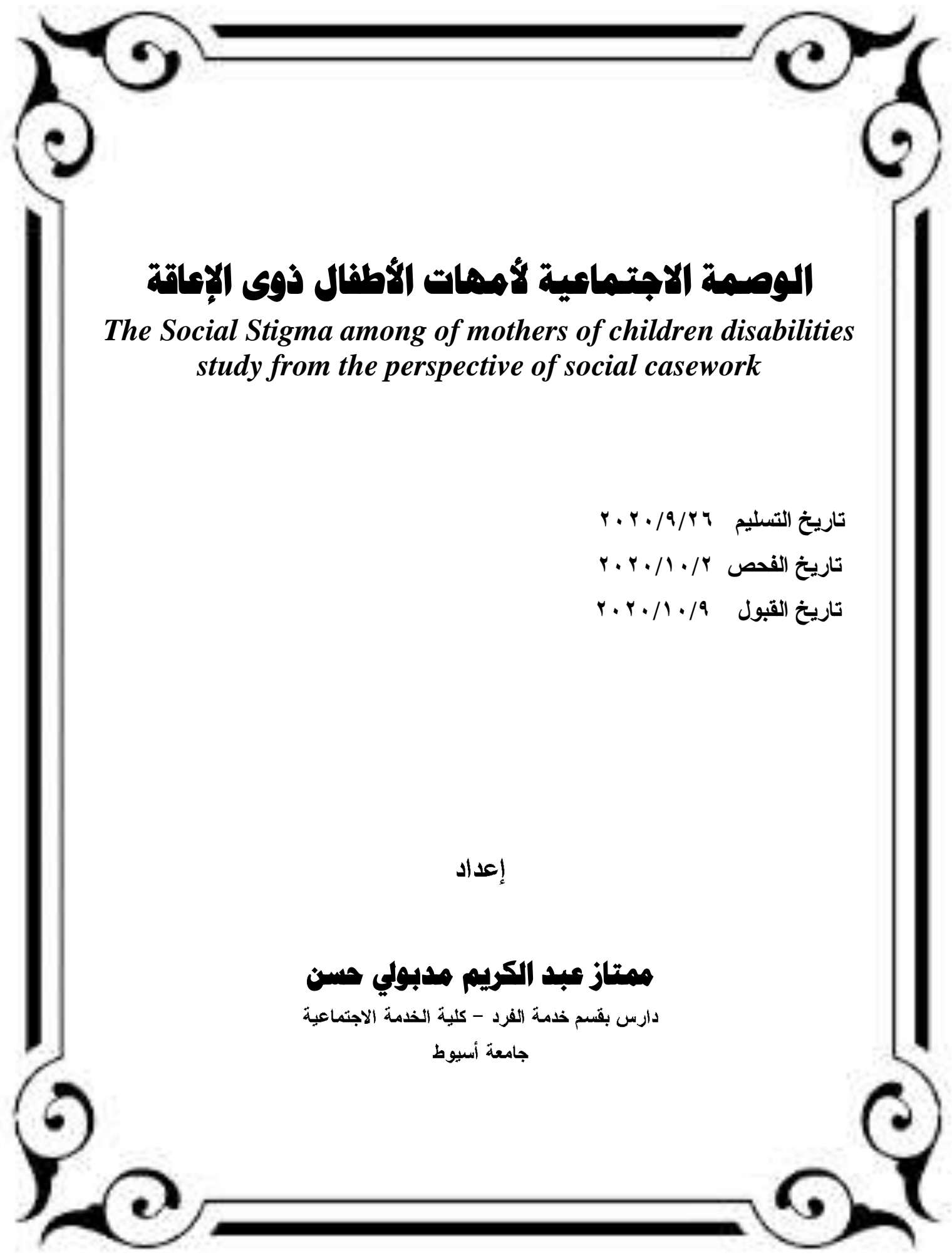





\title{
الوصمة الاجتماعية لأمهات الأطفال ذوى الإعاقة
}

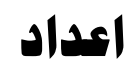 \\ ممتاز عبد الكريم مشدبولي هسن \\ دارس بقسم خدمة الفرد - كلية الحذدة الاجتماعية \\ جامعة أسيوط
}

\section{ملخص البحث:}

تمثلت مشكلة البحث في منغصات حياة أمهات أطفال التوحد هو تأصل الوصمة فـي حيـاتهن ، فالوصـــة

و الظلم الاجتماعي كالقبضة الملقة التي لا يمكن أن يتصافحا معاً ، فالوصمة متعلقة بقضية اللوم الاجتماعي ، استمدت فلته

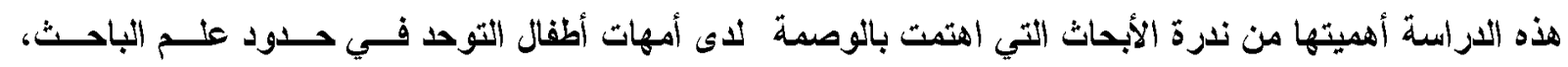

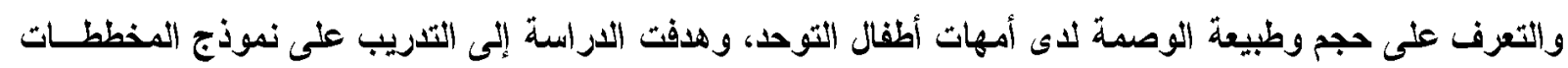

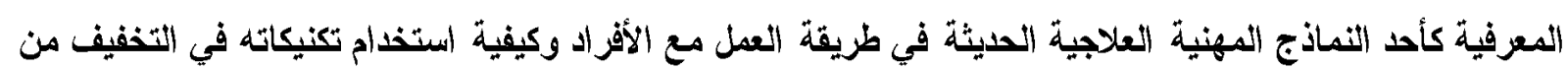

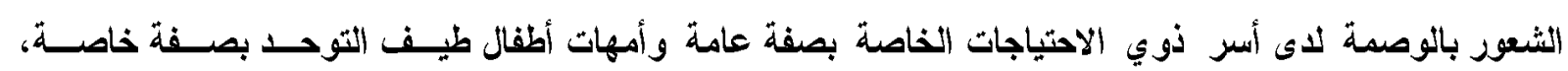

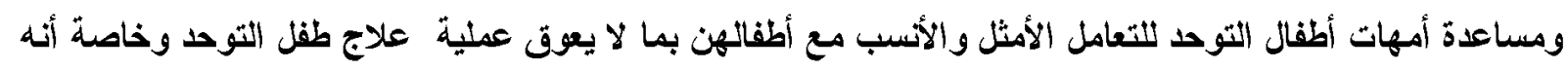

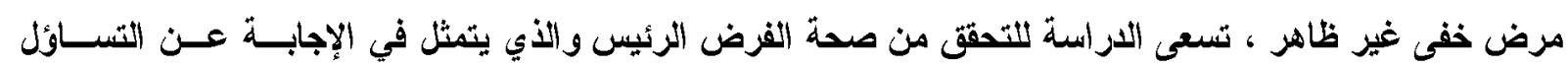

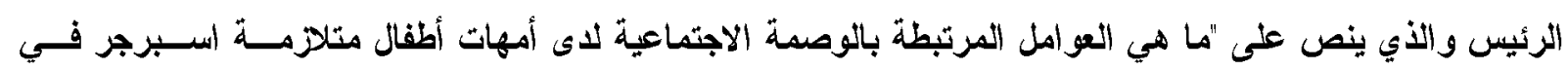

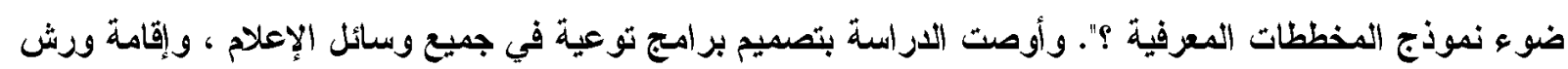

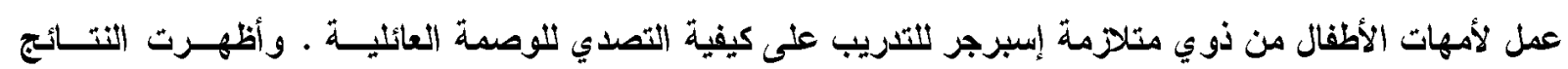

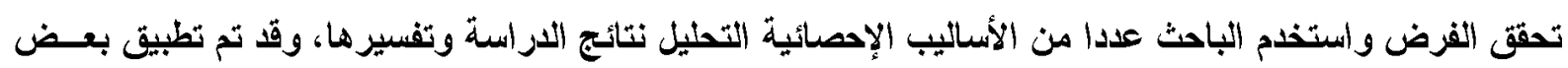

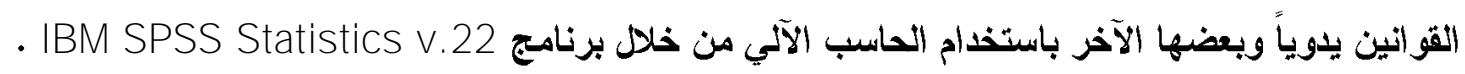




\begin{abstract}
The problem of research in the troubles in the lives of mothers of autistic children is the inherent stigma in their lives. Stigma and social injustice are like a clenching fist that they cannot shake hands together. The stigma is related to the issue of social blame. The researcher, learning about the size and nature of stigma among mothers of autistic children, and the study aimed to train on the model of cognitive schemes as one of the modern therapeutic professional models in the method of working with individuals and how to use its techniques to reduce the feeling of stigma among families of people with special needs in general and mothers of children of the autism spectrum in general. Especially, and helping mothers of autistic children to deal with their children in an optimal and appropriate way that does not hinder the process of treating an autistic child, especially as it is an invisible, hidden disease. Mothers of Children with Asperger's Syndrome in Light of the Cognitive Diagrams Model? The study recommended designing awareness programs in all media outlets, and holding workshops for mothers of children with Asperger's syndrome to train on how to combat family stigma. The results showed that the hypothesis was fulfilled. The researcher used a number of statistical methods to analyze and interpret the results of the study. Some laws were applied manually and others were applied using computers through the IBM SPSS Statistics v.22 program.
\end{abstract}


خاصية من خصائص الجسم أو العقل أو النفسـية أو

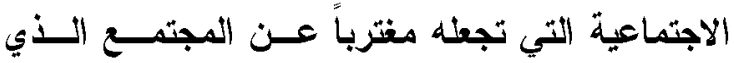

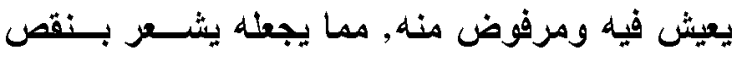

التوازن النفسي والاجتماعي (Deborah,2001). فالتوصدة تعني ردة فعل الجههور تجاه مجموعة من

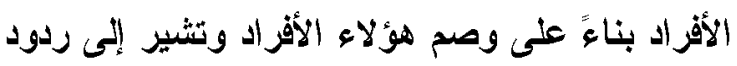
أفعال الأفزاد الأين ينتمون إلى المجموعة الموصومة المهي وتحويل المواقف ضدهم (Rusch,2005).

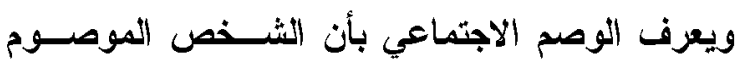

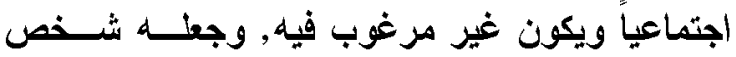
منبوذ اجتماعياً, لأنه فرد مختلف عن باقي الأفز اد لأي

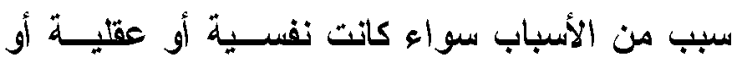
اجتماعية (Goffman, 1998).

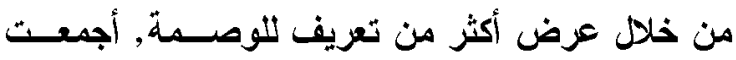

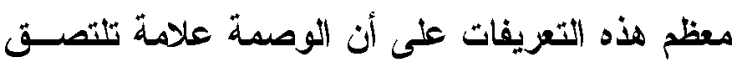

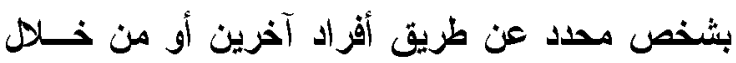
جماعات اجتماعية, وتكون موجهة اتجاه شخص بريث بعينه

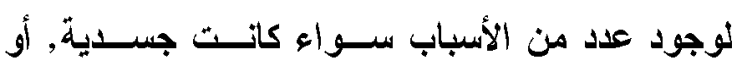

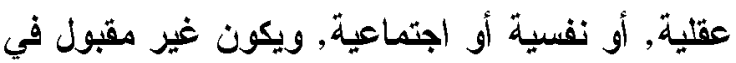

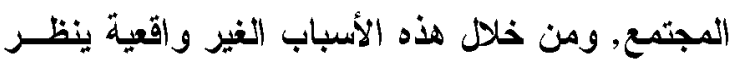

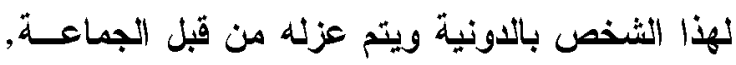
وهذا الأمر يحرمه من التقبل والتأييد الاجتماعي.

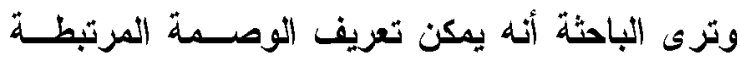

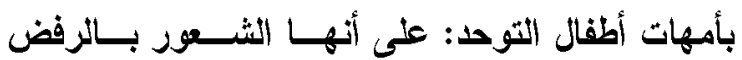

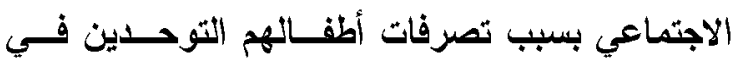
المواقف المختلفة, وتنظر فيها أمهات الأمور بسـلبية بسبب سلوكيات أطفالهم المضطربين, ورهذه النظــر ات

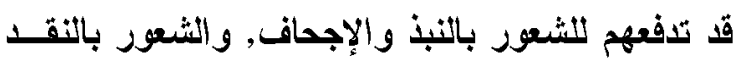

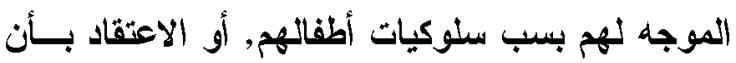

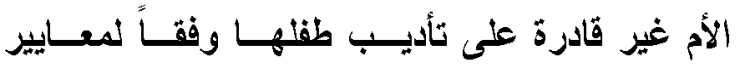

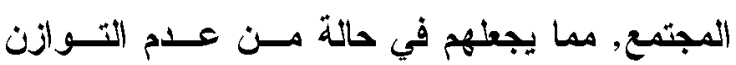
النفسي والاجتهاعي. لمة تاريخية عن الوصمية: تزجع وصمة المرض النفسـي إلـــ الاغزيــق فــي

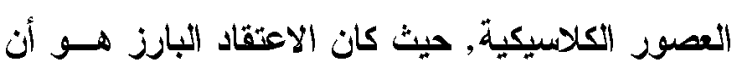

\section{مقدمه}

تعتبر الوصمة ظاهرة اجتماعية معقدة جذاً, وقد تبرز

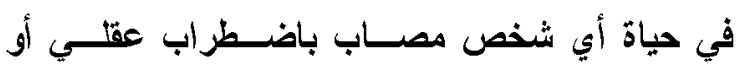
نفسي, تكمن الوصمة بردود الفعل العاطفية السـائدة

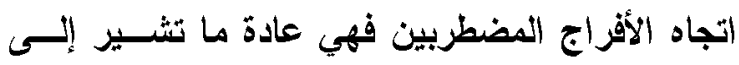
مجموعة من المواقف والمعتقات السلبية, التي تحفز

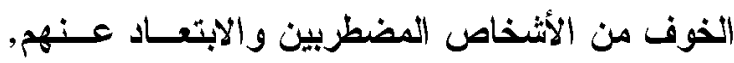

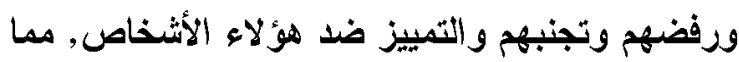

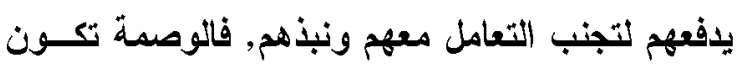

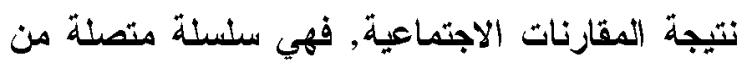

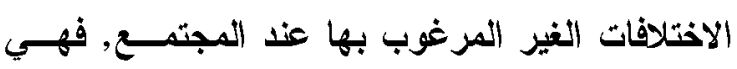
تثؤدي إلى التقليل من ثيمة الآخرين و الثعور بالتفوق

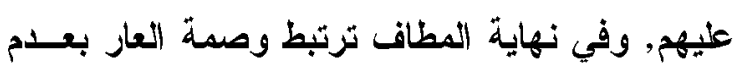
المساو اة الاجتماعية.

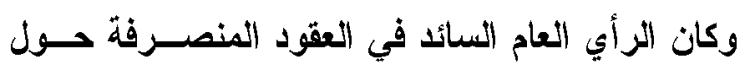

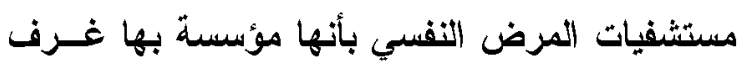

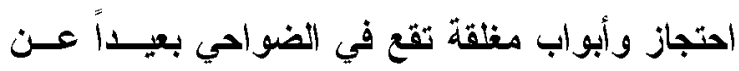

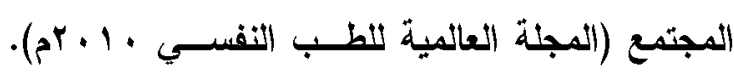

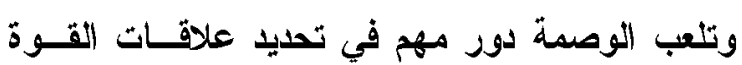

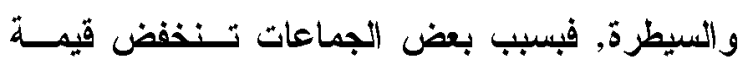
بعض الأفر اد مما يؤدي إلى عدم المساواة الاجتماعية

.(Parker, 2003) تعريف الوصمة لغة: وصم, عيب وعار وصمة عار - إنه يزى وصمسة غيره ولا يزى وصمته: ما يعب وينال من الثرف. وهن.

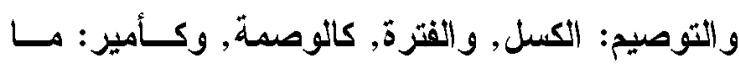
بين الخنصر والبنصر .(الفيروزي, د.ت. ولتهن

وصمة, وسم, علامة مميزة Stigma

تعريف الوصمة اصطلاهًا:

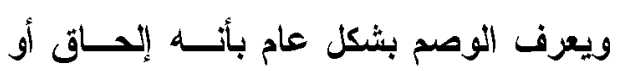

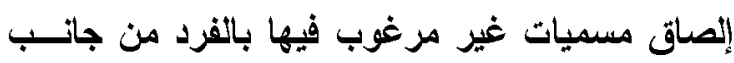

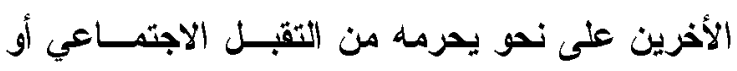

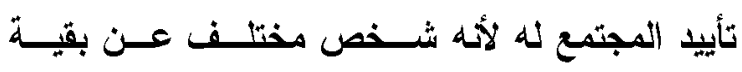

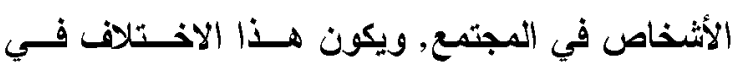




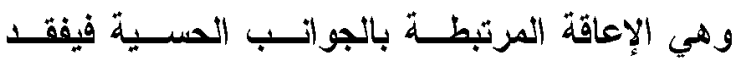

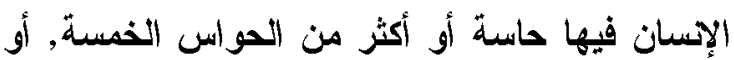

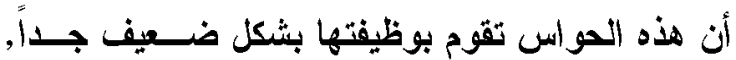

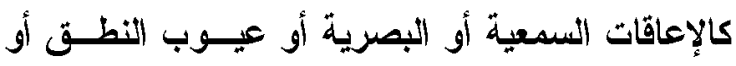
الكلام واضطر ابات الشم واضطر ابات التذوق واللمس لإن التس

$$
\text { (أبو النصر , همة ه. . بمة) }
$$

هي الوصمة المرتبطة بعيوب استخدام اللغةت والكـلام, مما يؤدي إلى نطق غير صحيح للحسـروف والكلمـات وتؤدي إلى اضطر ابات كلامية مثل اللجلجة والتهتئهـئة و الفأفاة أو الخنف أو عدم القدرة على تنغيم الكثــات التهات

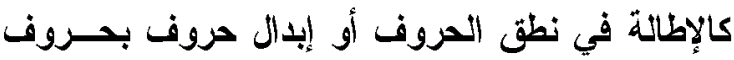

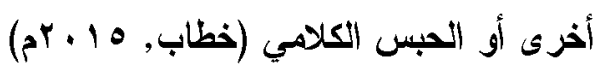

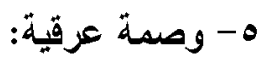
هي الوصمة المتعقة بـاختلاف الســلالة, والــوطن والدين, وما يتتج غنها مسن اختلافِـات ســواءوفـي

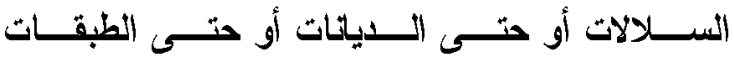
الاجتماعية, وتعاملها ميع الطبقات الدنيا باعتبارها أنها أقل مكانة, ومن خلالها أعطت الطبقات العليا نفســها الصلاحية لوصم هذه الطبقات والتقليل مسن مكانتهـا وحقوقها, وأدى هذا إلى التبييز العنصري, وان هـــا موجود على سبيل المثال في أمريكا وجنوب أفزيقيـا

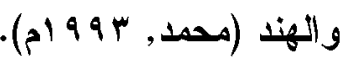

ويمكن أن تكون هذه الوصمة المتعقة بالاختلافات بين البشر , وتثؤدي إلى خفض قيمة الآخرين بـين البثـــر

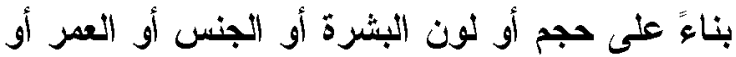

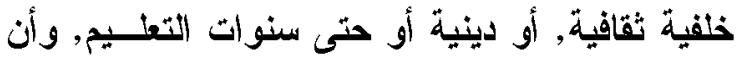

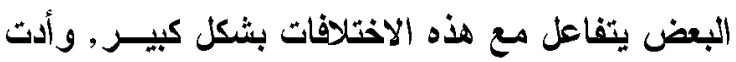

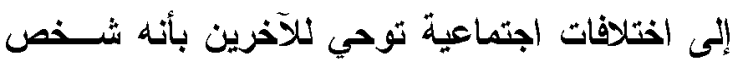
غير مرغوب فيه (Lennard,2013).

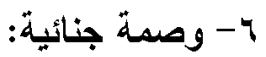
هي عبارة عن اطلاق تهمة أو صفة سـلبية وغيـر

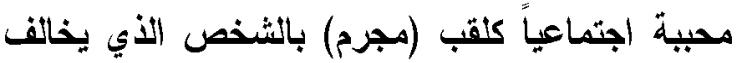

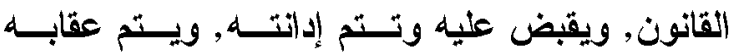

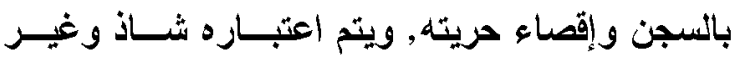

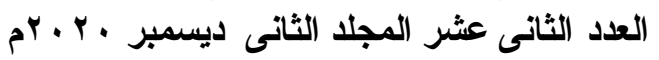

المرض النفسي هو بمثابة استياء وغضب الآهة مما

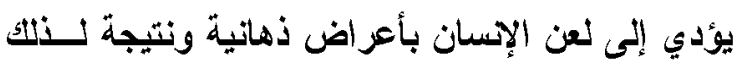

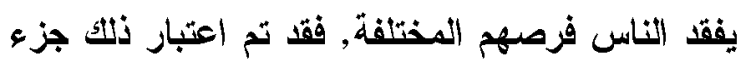
من التلاهوت, فكانت نظرة رجـال الــدين للأثــخاص المصابين بالمرض النفسي عـــى أنهــا مـن إنتـاج الثياطين والأعراض الظاهرة على الإنسان هو نتيجة

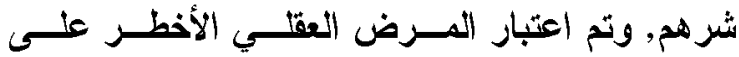

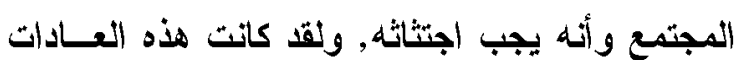

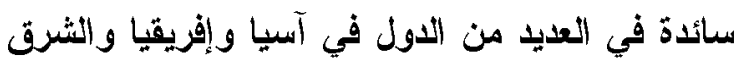

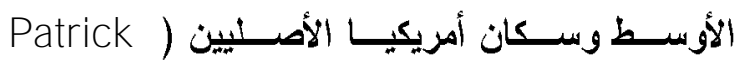
.(William, 2010 أهم صور الوصم الاجتماعي: 1- 1 - وصمة جسمية: وهي الإعاقة الجسد حيث أنها يمكن أن تتقســـ إلــى إعاقة صحية, وإعاقة جسدية, والإعاقة الجسدية قهـ

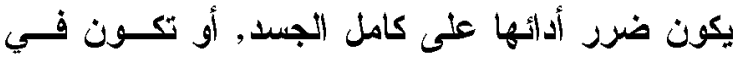

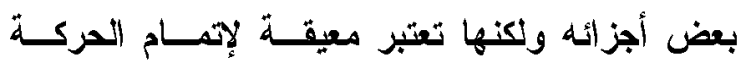

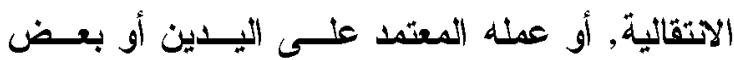
أجز ائها, وقد تكون عصبية كالثلل الدماغي وأضــرار الحبل الثوكي وأضرار العدود الفقزي, الاضـطر ابات

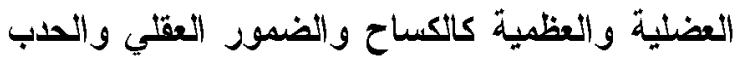
والبتز , وقد تكون في جوانب عدم الاتزان الانفعالي أو وانويه

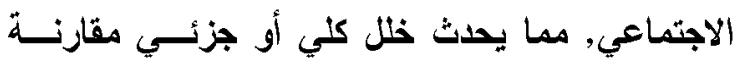
بالأفر اد الاصحاء (محمود, · 1 • rم).

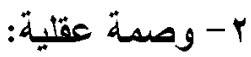
تكمن في القصور الفكري والوظيفي, ويكون ناتج عن عدد من العوامل منها وراثية أو البيئية أو ناتجة عن وني

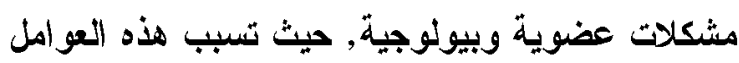
عجز في الجهاز العصبي يترتب عليه ضعف قـدرات

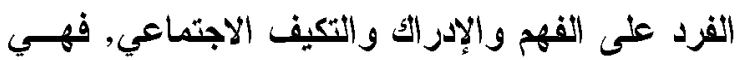
حالة تؤدي إلى عدم اكتمال النمو العقلي للفرد فتجعله

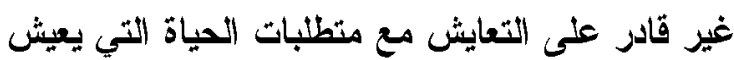

$$
\text { فيها (أبو النصر , ع ـ . بام). }
$$


الوصمة الاجتماعية لأمهات الأطفال ذوى الإعاقة مستاز عبد التكريم مدبولي حسبن

وغاياته ويلتزم بقو اعده وبالتالي تقلل مـن إمكانيـة

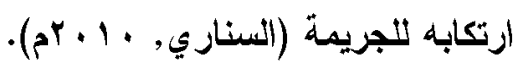

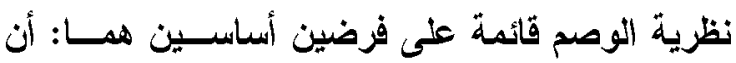
الاحمر اف لا يقوم على نوعية الفعل بل علــى نتيجـة

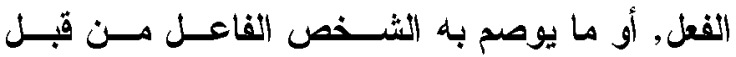

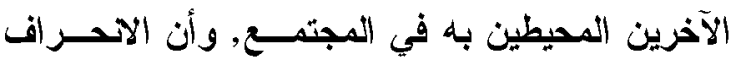

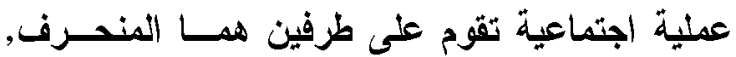
وردة الفعل الاجتماعي (العتيبي, ؟ ... بم). الوصسمة الاجتماعية هن هنظور إسلاهي:

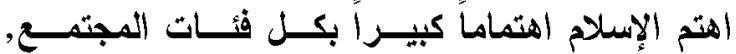
وحرص على تعليم المسلمين طرق رعايــة الضــعفاء وذوو الاحتياجات الخاصة, وكفــل الــدين الإسـلادي حقوقهم فحرص على هذه القلة وعمل على رعـايته

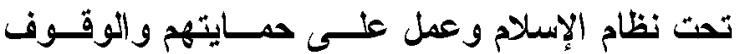
بجنبه و إيجاد من يساعدهم, وعليه جـاءت الآيسات الكريمة في كتاب الله تعالنى لتؤكد للجميع أن الله تعالى لهي

يحث على نصرة الضعيف وإعانته قثر الاستطاعة. فالدين الإسلاهي لا يقبل تحقير الإنســان والســخرية

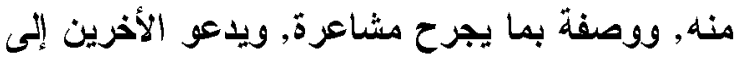

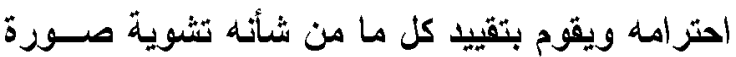

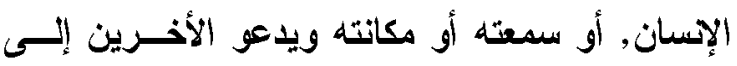
تقبلهم في المجتمع و التسامح و الصفح و العفو.

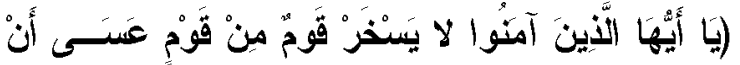

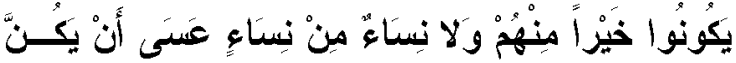

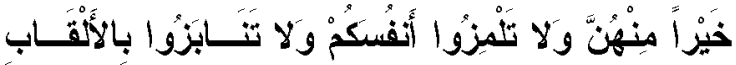

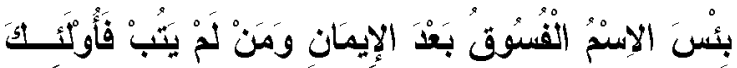

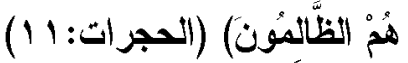
ويتبين من الآية الكريمة جزءء من آداب الدين الحنيف

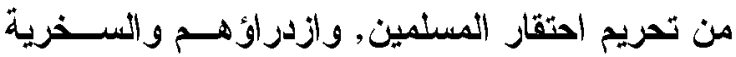
منه و الاستهزاء به و الحط من قدره, وتكمن الحكمسه

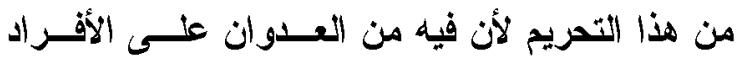

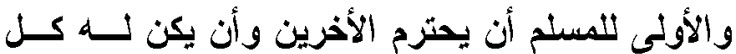
تقر , وخاصة إذا كان هذا الفرد من ذوي الاحتياجات

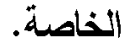

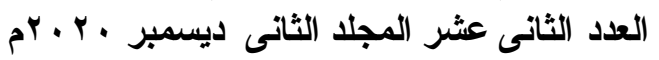

سوي وموصوم جنائياً, وتبقى هذه الصفة تابعه له في

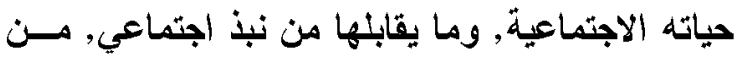

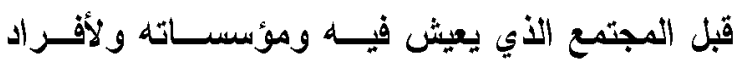

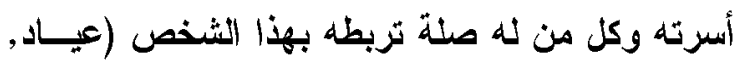
.$(5, \cdot$.

من خلال ما سبق تزى الباحثة أنه تعدد أنواع التوصدة

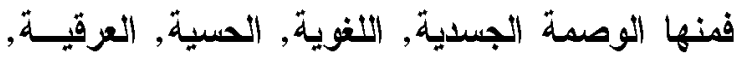

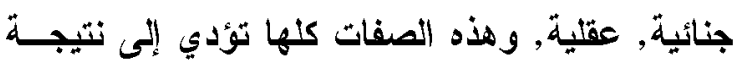

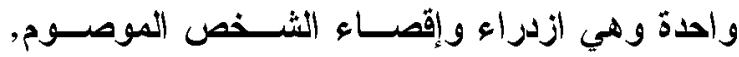
وتبقى هذه الصفات عالقة بتاريخ الثخص الاجتماعي,

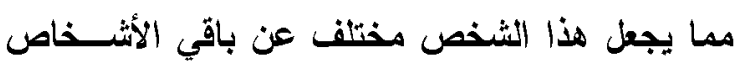
من وجهة نظر المجتمع.

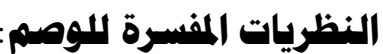
حاول العالم شوهام (Shawham) أن يقوم بتحديـــ

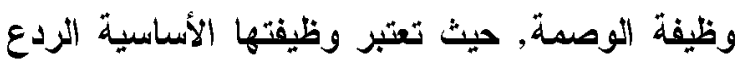

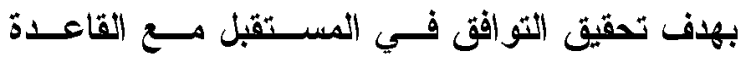
القانونية, وكن أصبح لها أثز رادع بصــورة دائمسـة

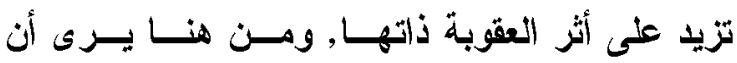

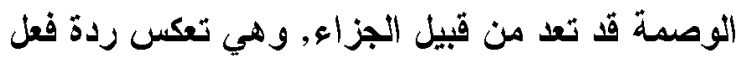

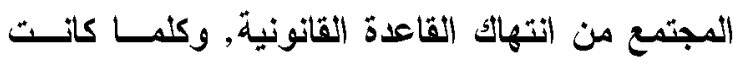

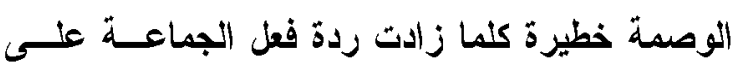

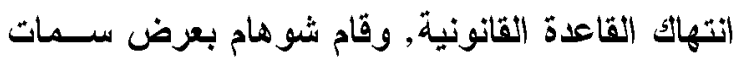

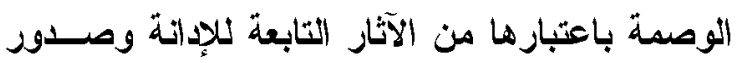
حكم بعقوبة جنائية, ويؤكد أن الوصمة في التشريعات التان

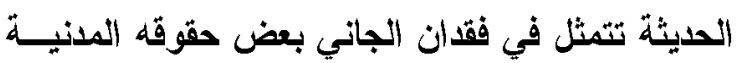
كحق الوظيفة والزواج وغيرها.

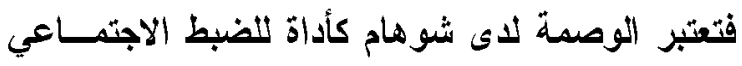

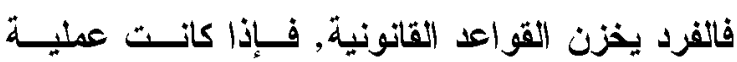

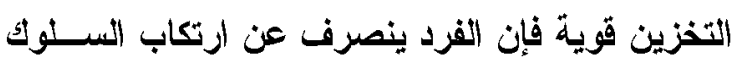
الإجزامي خوفاً من الجزاء, وهنا تكون للوصدة أتخـر كبير باعتبارها جزاء.

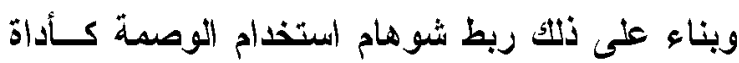

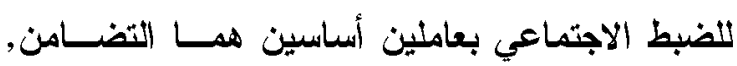
والانصياع فالفرد يتحدد سلوكه من خلا نظرته لهنين لهامين

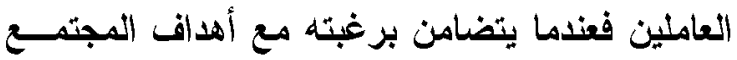


أمتي من يأتي يوم القيامة بصيام وصلاة وزكاة ويأتي قد شتم عرض هذا, وقذف هذا, وأكل مال هذا, فيقعد

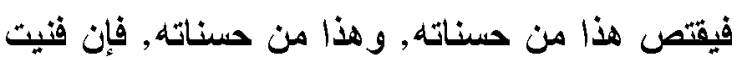

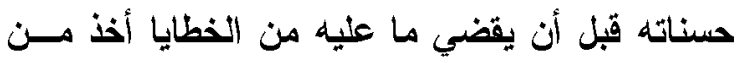

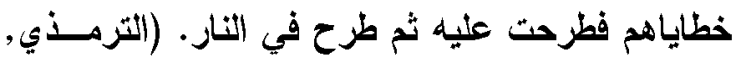

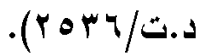
وقد أعطى الإسلام لذوي الاحتياجات الخاصة حقوقهم فحرص على دمجهم في مجتمعهم, كما حرص الإسلام إلى توجيه المجتمع والمحيط الذي يعيث فيه الثخص

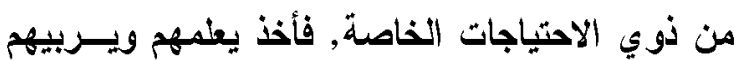
على السلوك الأي يجب أن يســلكوه في في معساملتهر لإخوانهم من ذوي الاحتياجات الخاصة فهـو إعـلان

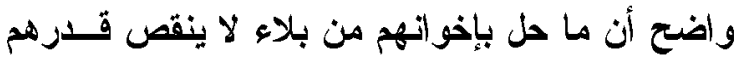

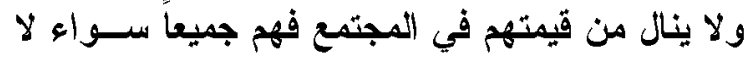
تفاضل بينهم إلا بالتمقى فقد يكون أفضل وأكرم عنـــ الله من ألف صحيح معافي فقال تعالم (إن أكرمكم عند الله أتقاكم) فالميزان الحقيقي هو التقوى وليس المسال أو الجاه أو الصحة أو الصورة الخارجية أو غير ذلتص لأله لا يمكن أن تتحقق الغاية السامية من هذه الحياة إلا إذا تحقق ميزان التققى, هذا الميزان الأي له وقع اله

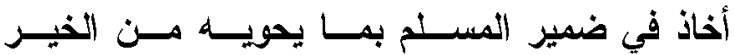

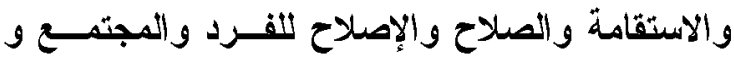
ليلإنسانية جمعاء.

\section{الوصيمة وأههات الأطفال المعاقين}

عادة ما تواجه أمهات أطفال التوحد تحسيات فريدة من نوعها بسبب السلوكيات العامة التي يقوم بها طفلهـا

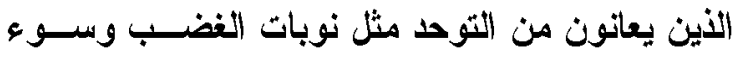

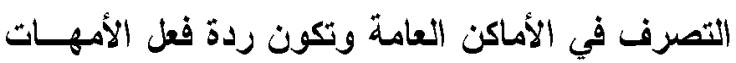
غير سارة بسبب ردود فعل المشاهدين مـن المــارة. فرعاية طفل يعاني من اضطراب التوحد عملية صعبة وينتج عنها ضغط هائل للأم, وتوجــ حاجـة ملدسة

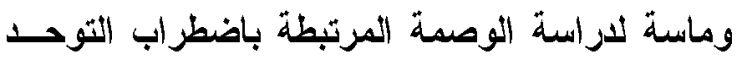

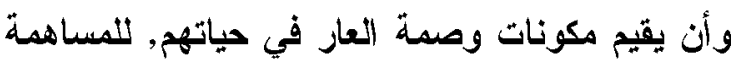
في سد هذه الفجوة.

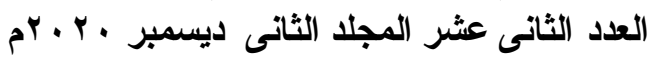

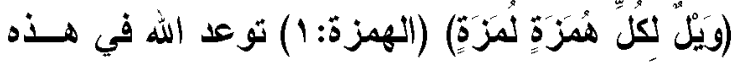
الآية بالعذاب للشخص الأي يستهزئ بالناس ويعيبه ويطعن فيهم سواء بالقول أو الفعل.

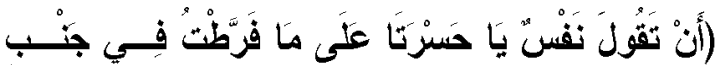

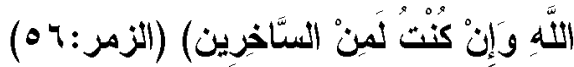

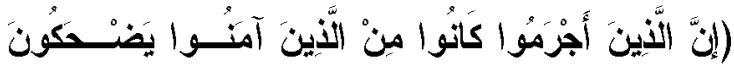

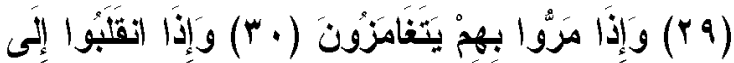

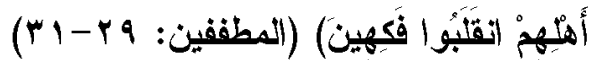

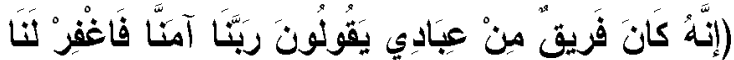

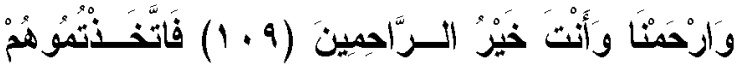

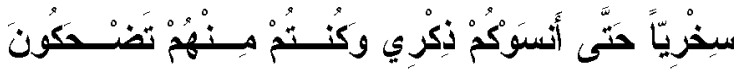

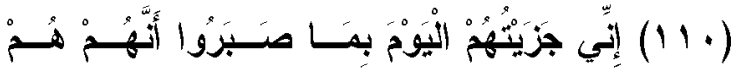

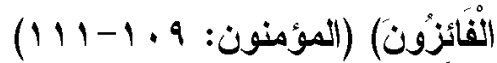

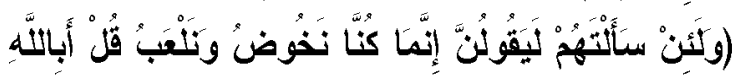

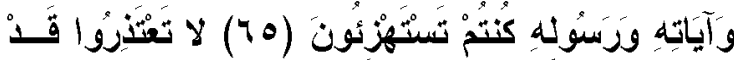

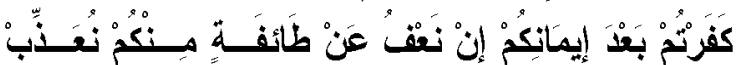

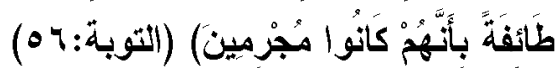

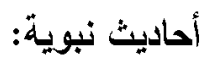
وروى البخاري في صحيحه من حديث المعرور قـال: لقيت أبا ذر بالربدة وعليه حلة وعلى غلامسـه حـــة,

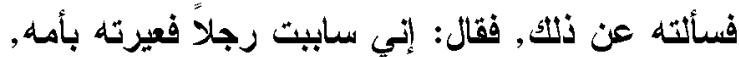

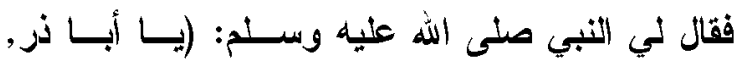

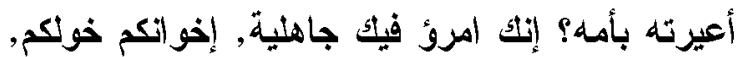

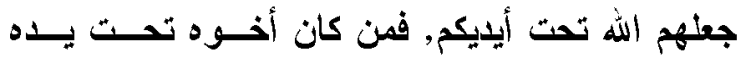
فليطعده مما يأكل, و ويلبسه مما يلبس, ولا تكفوهم ما هال

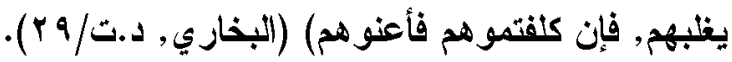
وروى أبو داود في سنته من حديث عائشة رضي الله

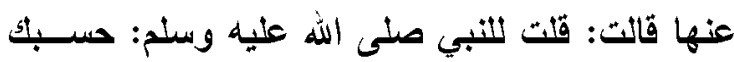

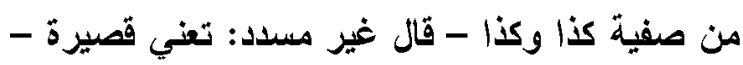

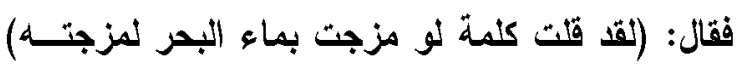

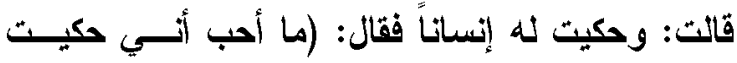

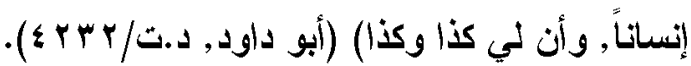
وعن أبي هريزة عن النبي صلى الله عليه وسلم قال:

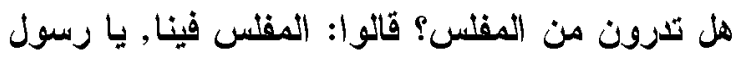

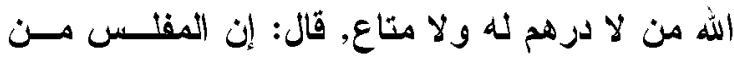


عن باقي الأفراد لوجــود التثـــوهات الجســية, أو نفسية, أو لتشوهات هوية الأفراد أو بسبب جرم قدام باه الثخص فيعاقب عليه طوال حياته, ويحرمه مسن

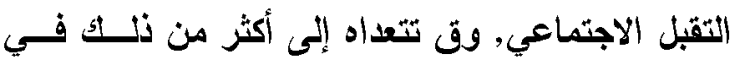
العليد من الجوانب سواء في الإجاب والزواج, مدسـا يجعل الثخص الموسوم في حالة من عــدم التــوازن النفسي والاجتماعي, وقا عزفت الوصدة على أنهـا إلصاق مسميات غير مزغوب بها للأفراد وتحسرهه

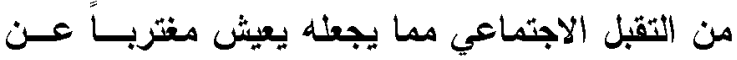

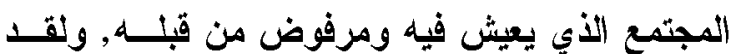

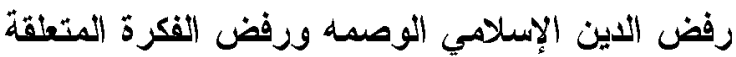

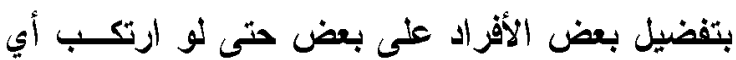
جرم يعاقب عليه الفرد.

\section{المبحث الثالث: المشكلات النفسية والاجتـهاعية} تربية طفل مصاب بالتوحد يعتبر بمثابة تحد للوالاين,

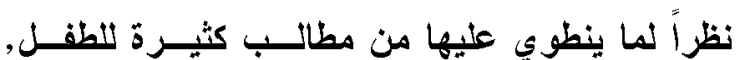
فهؤلاء الآباء يمرون بضغوط أكبر من آباء الأطفــال

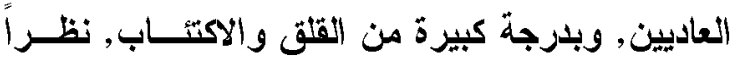
لأهله لا يوجد علاج قاطع للتوحد حتى الآن , فنلت يضع عبئًاً إضافياً على الأسرة في تحمل مسؤوليات تربيتها

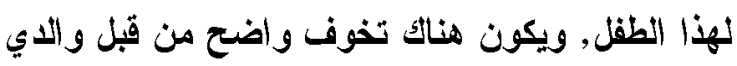
الطفل المصاب بالتوحد تجاه مستقبله, على اعتبار أنه

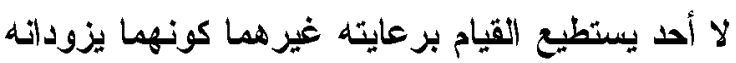

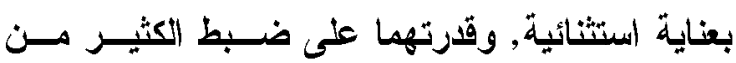

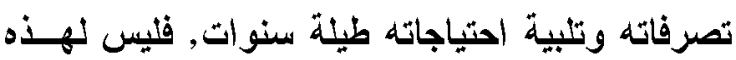

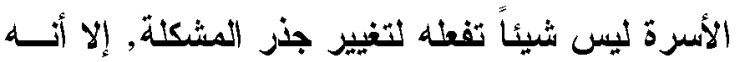
مدن الممكن أن تتبع مجموعة من الاستراتيجيات التي

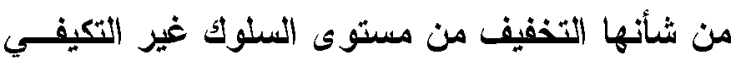
وزيادة قدرة الطقل على التعايش. وعليه فإنا إخراج الطقل التوحدي إلى المجتمع يمكـن

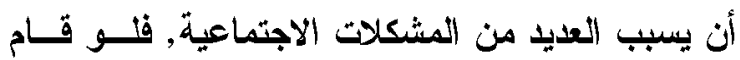

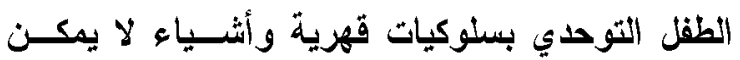

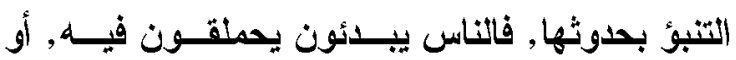

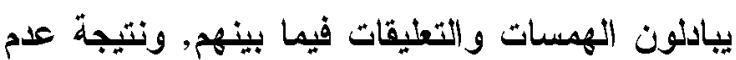
قدرة الناس على تفسير بعض السلوكيات التي تصــدر

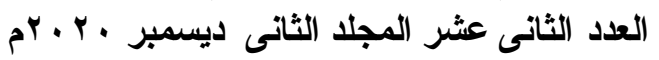

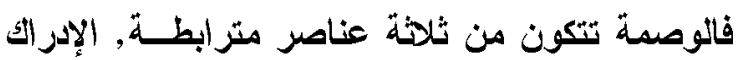

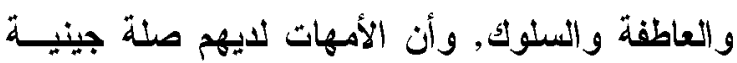

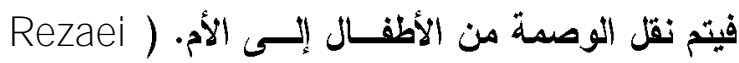
.(Dehnavi, 2011 إدر الك التاس للأطفال التوحلين يكـون مختانـف عـن

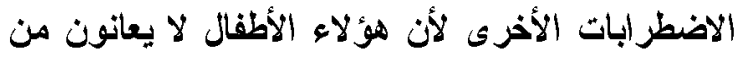
تشوهات تلدل على طبيعة اضطر ابهم, فيقومون بإطلاق

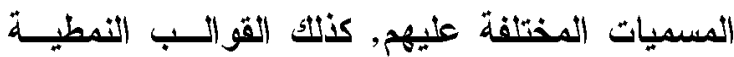
لهؤلاء الأفر اد في التفكير تدفعهم لعدد من الأفتراضات

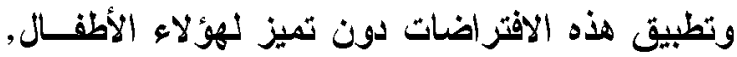

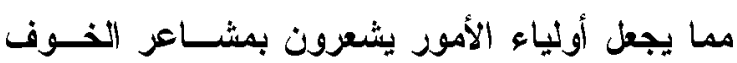

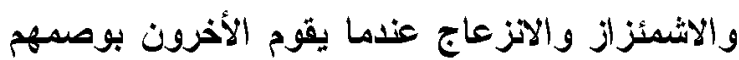

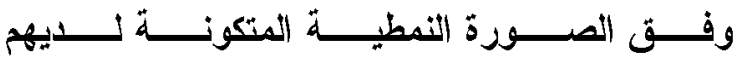

(Sydney,2016)

أثبتت الثراسات ومن بينها دراســة (Celia,2016)

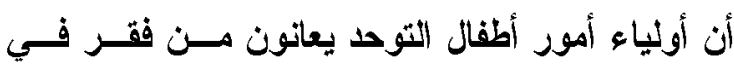

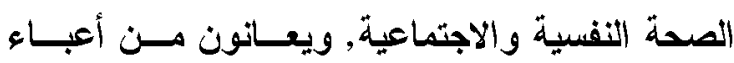
إضافية في رعاية أبنائهج, أكثر من أولياء أمور أطفال

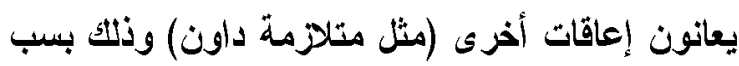

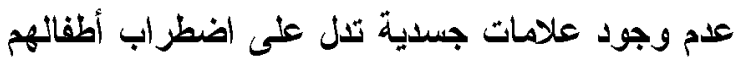

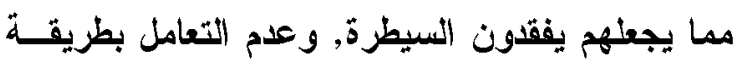

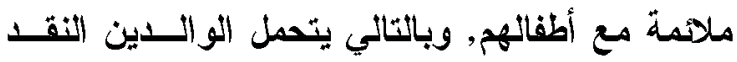

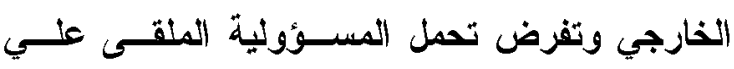

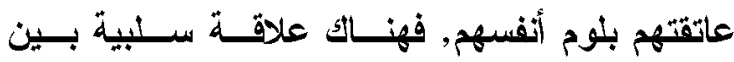
الوصمة وأولياء أمور أطفال التوحد.

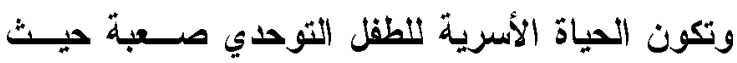
يغلب عليها الروتين وتصبح متمحورة حول احتياجات الطفيله الطفل وتتحول إلى أنشطة روتينية صارمة تحكم كـلـيل

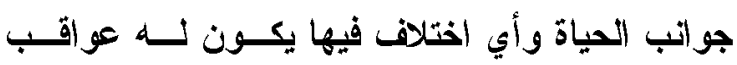
وخيمة (David,2009). خلاصة القول تكمن في اعتبار الوصـــة مستن أكثــر الظواهر الاجتماعية تعقيداً بسبب الأشخاص وتفضـيل فيليل

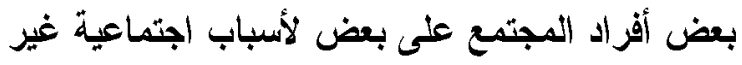

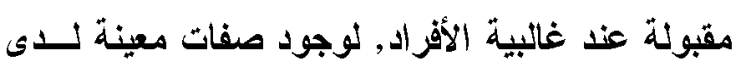

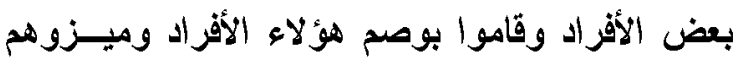


الوصمة الاجتماعية لأمهات الأطفال ذوى الإعاقة مستاز عبد التكريم مدبولي حسبن

على مثكلة محددة بل يتجه إلى أبعد من ذلتك ليثــمل معظم المشكلات الاجتماعية ويقوم كل باحث بتحديدها

من خلال ما ينظر إليها.

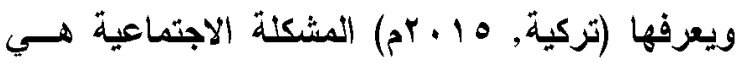
موقف اجتماعي يقتضي تغييراً إلم الأفضل ويبحث في الاجني

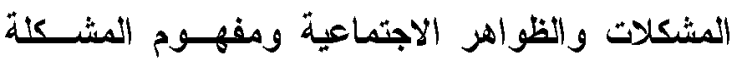
الاجتماعية وأنواع المشكلات الاجتماعية لأن المشكلة الاجتماعية مصادر متعددة, ويتناول النظم الاجتماعية

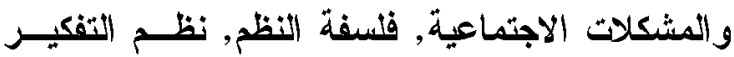

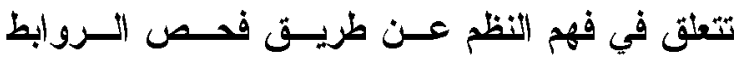
و التفاعلات بين العناصر التي تؤلف مجمل النظم. وتعرف بأنها صعوبات وانحرافات سلوكية تظهر على لغل

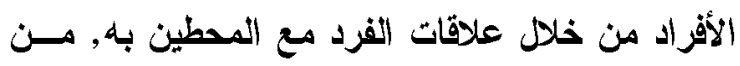

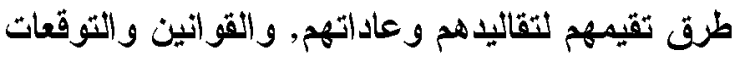

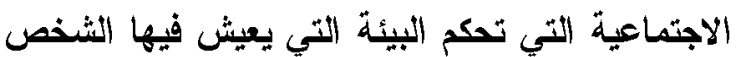

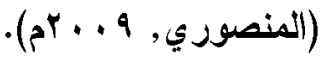
يعرفها أبو دف: أنها الأخطاء السلوكية الصادرة عن الأقر اد في أقو الهجم وأفعالهم في المجــالات العقائديــة

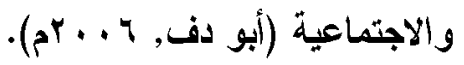

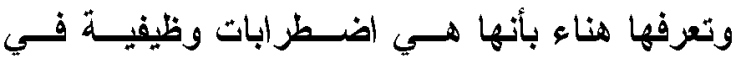
الثخصية, قد تكون نفسية المنثأ وقد تبدو في صورة

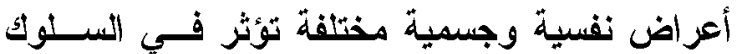
الثخصي فيعوق تو اققه النفسي ويؤثر على ممارســة حياته السوية في المجتمع الذي يعيش فيــه (هنـــاء, $\cdot(a r+r$

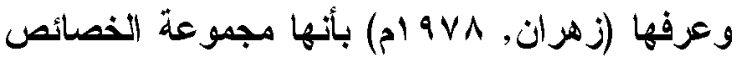
المتمثلة في نقص القدرة والارتبـاتك فـي المســائل الاجتماعية, و الخوف من مقابلة الناس, ونقص القدرة

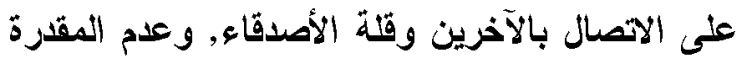

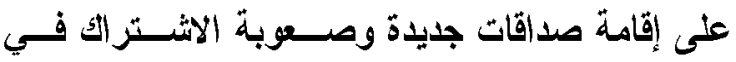

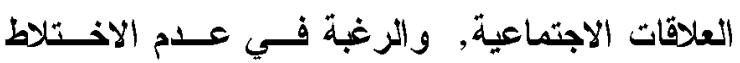
الاجتماعي, وقثلة النشاطات الترويحية مع الأصدقاء. المشكلات وأمهات أطفال التوحد: اضطراب طيف التوحد (ASD) كما هو معروف عنــه بأنه اضطراب يتميز المصابين فيه من ضعف الاتصال

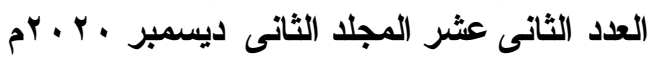

من الطفل أو الحكم عليه من شكله العام نتيجــة أن الطفل التوحدي لا يعاني من أبي مثكلات في الثـــكل

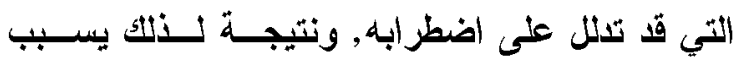

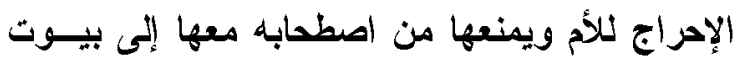

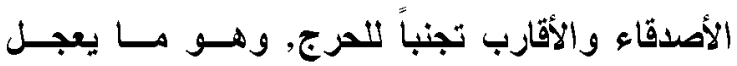

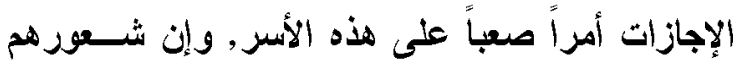

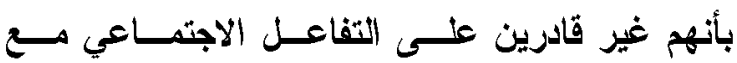

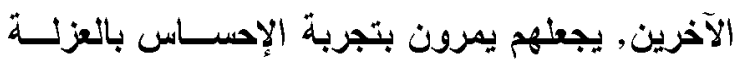
عن أصدقائهم, وأقاربهم و المجتمع عامة.

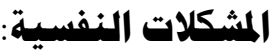
تعرف المشكلات النفسية بأنها هـي مجموعـة مسن المشاعز المختطة التي تسبب للفرد صراعات داخلية

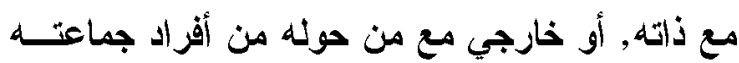

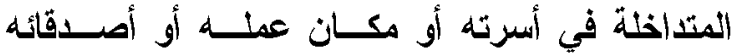

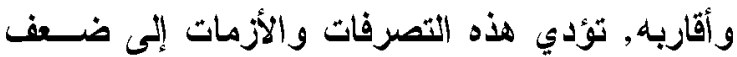
التوافق الثخصي وتحرمه من الهناء بالصحة التفسية

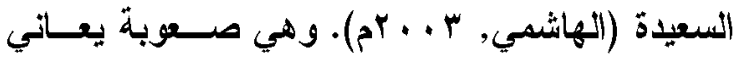

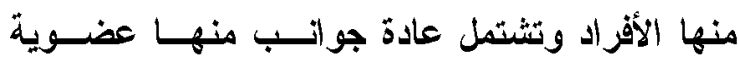

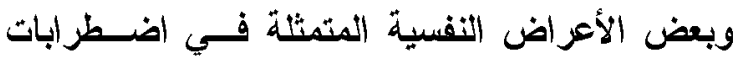
التفكير والاضطر ابات الاففعالية (الجولاني, ؛ ـ. . بم). وقد تكون اضطر ابات نفسية وظيفية نكون واضحة في

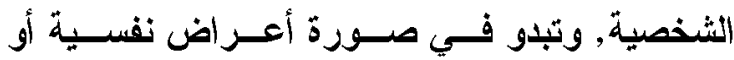

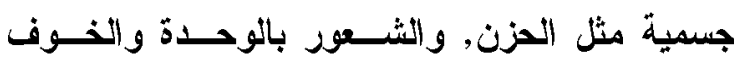

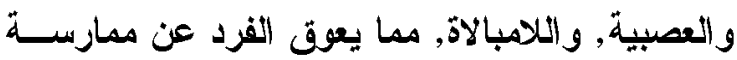

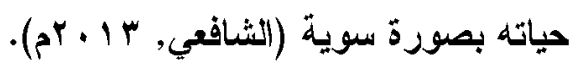
المشكلة النفسية: هي من وجهة نظر علم النفس بأنها

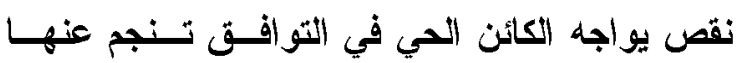
عوائق في سلوك وأهداف الثخص لا يستطيع بلوغها

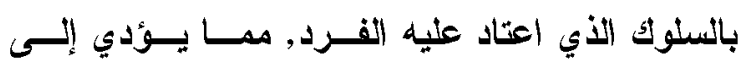

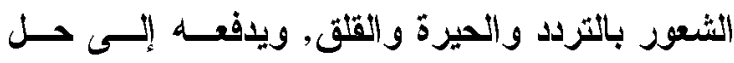

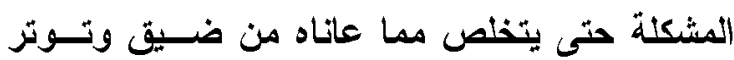

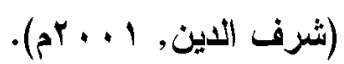

المثكلات الاجتماعية: تعتبر المثكلات الاجتماعية من الموضوعات المعقدة جـأ وذلتك بسبب عــدم إجـــاع العماء على رأي م عين في تعريفه, فهو غير مقتصر 
الوصـة الاجتماعية لأمهـات الأطفال ذوى الإعاقة مستاز عبد التكريم مدبولي حسبن

jarbrink, fombonne,\& ) النتـائج الســلبية. (knapp,2003

والقد اثبتت الدراسات منها دراسة (Benso,2006) (Glasberg et al, Hastings 2008, Marcus (et al. 2005, moes1995 أن آبـاء الأطفـال

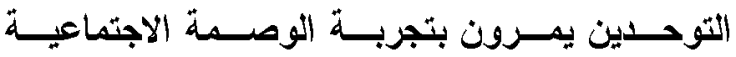
والإثصاء الاجتماعي, فهم يعيثون في عالم اجتماعي

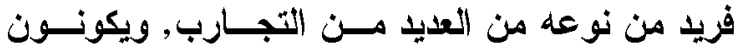

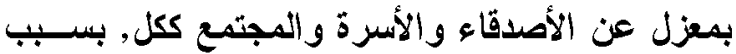
السلوكيات المتعقة بالتوحد (كالأعز اض والسـلـوكيات

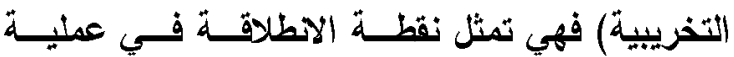
الوصمة, فكثير من ردود الفعل من قبل الآخرين ليست فيت لهيت على علم دائم بحالة الطقل, وقد تكون استجابتهم غير هند عقلانية لثئل هذه التصرفات كوجود افتراضات بعـدم

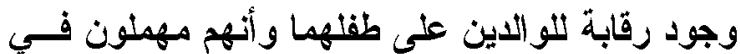

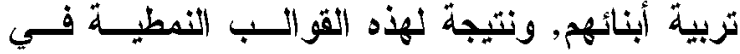
التفكير يولا الزفض من قبل الآخرين مما يدفع آبـاء

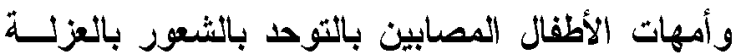

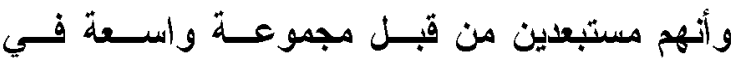

|

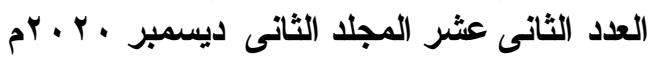

الاجتماعي, والحركات المكررة الروتينية, بالإضـافة

إلى ضعف الأداء الاجتماعي (الاجيمي

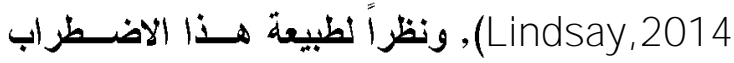
فإن أمهات الأطفال التوحدين (ASD) يواجهون بعض ونه التحديات الفريدة سواء في داخل المنزل أو الو في المجتمع (Pottie,2008) وتنتميز تجربة الأمومة

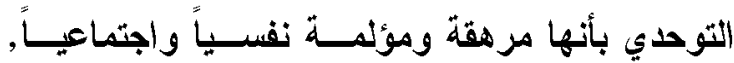

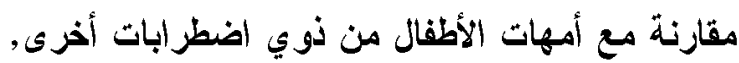

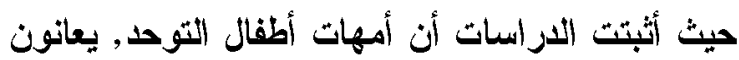
من مستويات أعلى فـــي الأعـــر اضل العاطفيــة مثـــل الإجهاد, و والقلق, و الاكتئاب. وتعثبر المثكلات النفسية والاجتماعية واحدة من أكثر والابر

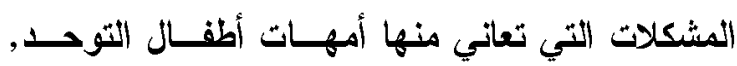

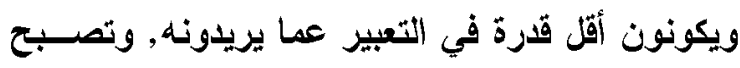

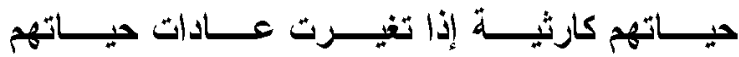

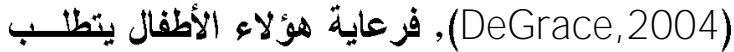

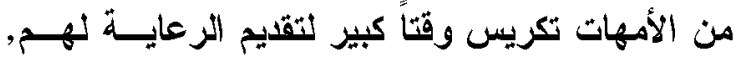
وهذا الأمر يقود إلى تعطيل دور رعاية بـاقي أطفــال العائلة, بالإضافة إلى العلاقات والأشثطة في مجموعة لإنة متنوعة من المجالات, كـــالموارد الماليـة، وتعطيـل الحياة الأسرية, مما يؤدي إلى الاكتئاب وغيرها مسن

جدول (1)

الاتساق الداخلي لمقياس الوصمة الاجتماعية لأمهات أطفال ذوي الإعاقة

\begin{tabular}{|c|c|c|c|c|c|c|c|c|c|}
\hline \multicolumn{10}{|c|}{ الأبعاد } \\
\hline \multicolumn{2}{|c|}{ المشكلات الاجنماعية } & \multicolumn{2}{|c|}{ المشكلاث السلوكية } & \multicolumn{2}{|c|}{ التبذ الاجتماعي } & \multicolumn{2}{|c|}{ العزلة الاجتماعية } & \multicolumn{2}{|c|}{ الرفض المجتمعي } \\
\hline & |لفقر| & الارتباط & |لفقر | & الارتباط & |لفقر| & الارتباط & |لافقر| & الارتباط & | الفقر| \\
\hline & ت & بالبعد & ت & بالبعد & 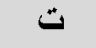 & بالبعد & ت & بالبعد & $ت$ \\
\hline$* . . \vee \circ 1$ & $\leqslant 1$ & $* .710$ & r & $* .799$ & Y & $* . \Lambda \cdot$ & 11 & $* . V Y 1$ & 1 \\
\hline$* * . \wedge r q$ & $\leqslant r$ & $* .799$ & rr & $* .741$ & rr & $* .701$ & ir & $* . \vee \wedge \Lambda$ & r \\
\hline$* .7 \wedge r$ & $\leqslant \psi$ & $* .7 \mathrm{~V} \varepsilon$ & $r$ & $* . . \vee \vee 4$ & $r r$ & $* .1 \times 40$ & $1 \%$ & $* . V Y r$ & $r$ \\
\hline & & & & * & & * & & & \\
\hline
\end{tabular}


الوصمة الاجتماعية لأمهات الأطفال ذوى الإعاقة

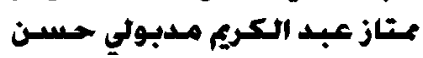

المجلة العلمية للخدمة الاجتماعية

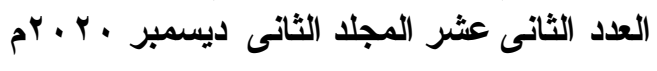

\begin{tabular}{|c|c|c|c|c|c|c|c|c|c|}
\hline *..VYo & $\varepsilon \varepsilon$ & *..v०r & $r \varepsilon$ & $* . . v, q$ & Y & $* . .797$ & $1 \varepsilon$ & $* . .79$. & $\varepsilon$ \\
\hline$* .701$ & $\leq 0$ & $\begin{array}{c}* . \vee \vee \vee \wedge \\
*\end{array}$ & o & $\begin{array}{c}* . \vee 79 \\
*\end{array}$ & ro & $\begin{array}{c}* . \vee \vee \vee \wedge \\
*\end{array}$ & 10 & *.VTO & • \\
\hline$* * . \wedge \backslash 1$ & $\leq 7$ & $* . .74 \%$ & ry & $\begin{array}{c}* . \vee \vee 9 \\
*\end{array}$ & r4 & $\begin{array}{c}* . \vee \wedge \varepsilon \\
*\end{array}$ & 18 & $\begin{array}{c}* . \vee V \vee \text {. } \\
*\end{array}$ & 7 \\
\hline$* .740$ & $\leq V$ & *..V4T & $r v$ & $\begin{array}{c}* . \vee q r \\
*\end{array}$ & TV & *. . TAr & iv & $* .794$ & $v$ \\
\hline$* * . \vee \wedge \bullet$ & $\leqslant 1$ & $\begin{array}{c}* \cdot \Lambda \cdot r \\
*\end{array}$ & rA & $* . .7 \leqslant 1$ & rA & *..Vד & 11 & $* . V .0$ & $\wedge$ \\
\hline$* . .719$ & $\leq 9$ & $* .7 \vee 9$ & rq & $* .7 r v$ & rq & $* . \vee \vee \diamond q$ & 19 & $*$ *.VYr & 9 \\
\hline$* * v a r$ & ๑. & $* . .749$ & $\leq$. & $*$ *.Vro & r. & $* . .779$ & $r$. & $*$ *.VYo & 1. \\
\hline
\end{tabular}

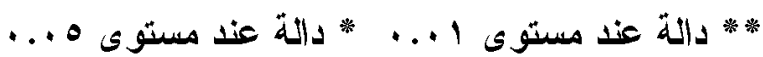

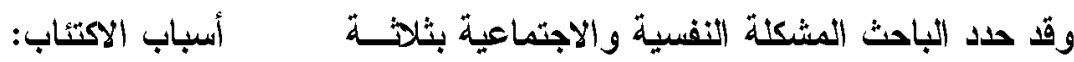

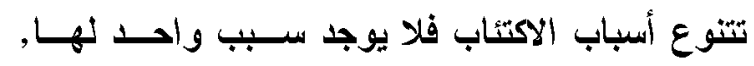

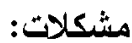

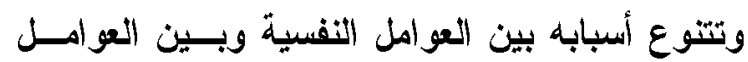

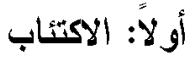

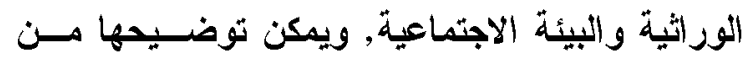
خلال الزسم التالي

الاكتئاب هو مزيج من المشاعر المختلطة الممزوجـة بين القلق و الحزن والتشاؤم, ويكون لهذا المزيج تأثير سلبي على أفكار الشخص وسلوكه ومشاعره, ويعـد

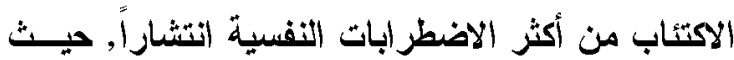

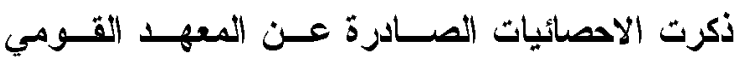

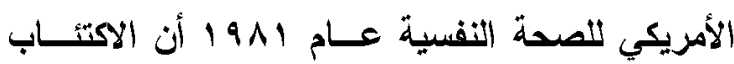

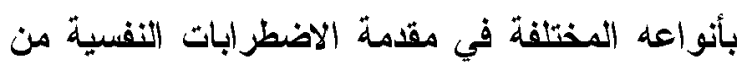

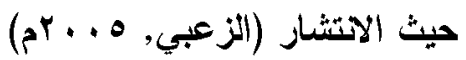

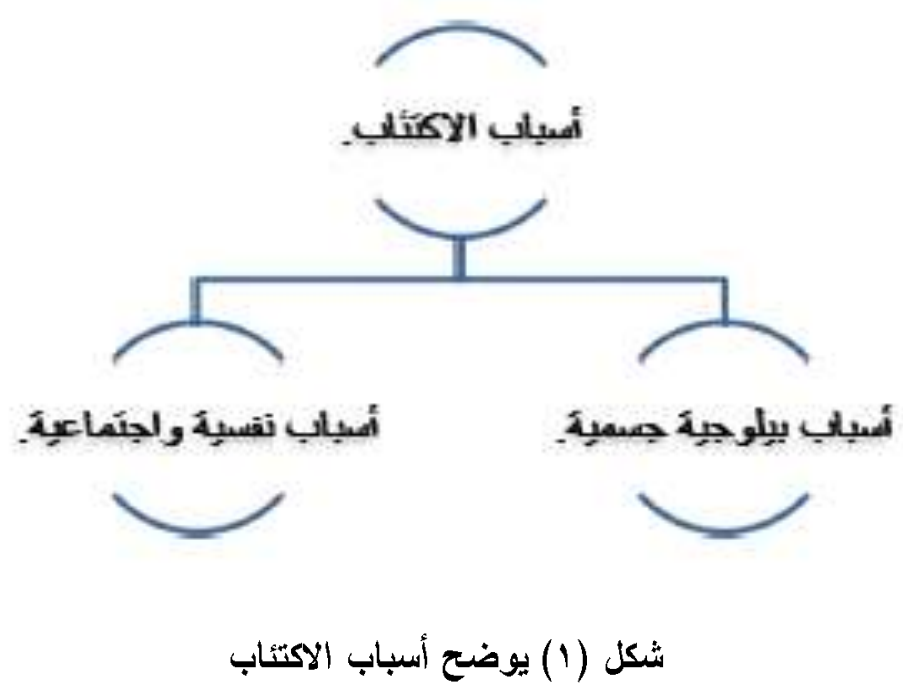


الوصمة الاجتهاعية لأمهات الأطفال ذوى الإعاقة

مستاز عبد التعريم مدبولي حسبن

- الخبرات الصادمة و التففير الغـــاطئ غيـر

التواقعي للخبرات.

- التربية الخاطئة.

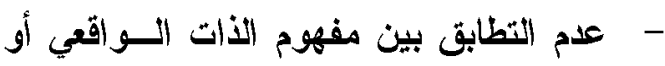

المدرك بين مفهوم الأات المثالي.

ثانياً: قثق المستقبل

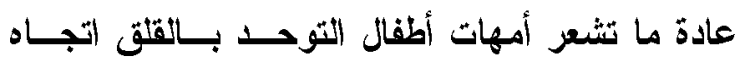

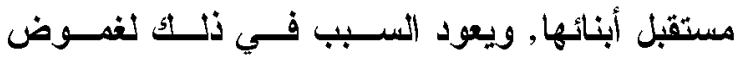
مستقبل هؤلاء الأطفال, وعدم القدرة على تحديد روئية و اضحة تجاه هذا الطفل ومستقبلة, بالإضافة إلى ذلأك ضعف الخدمات المقدمة لهؤلاء الأطفال مما يزيـ مسن لهن

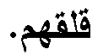

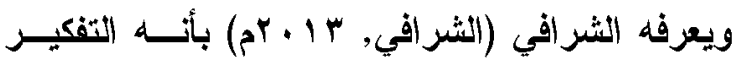
سلبية نحو المستقبل, والتطع بنظرة سلبي تثــاؤمية

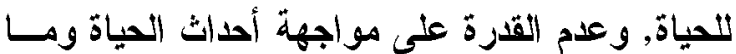
تصاحبها من مشكلات وضغوطات, مما يدفعه الثعور بالخوف وعدم الاطمئنان من المستقبل. وهو الثعور بعدم الارتياح والتفكيـر السـلبي تجــاه

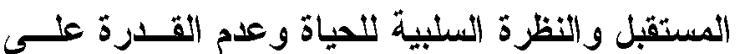
مواجهة الضغوط والأحداث الحياتية وتدني اعتبـارات

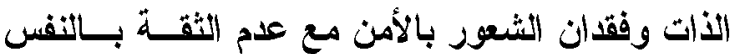

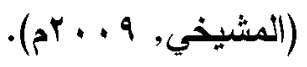

وتعرف الجمعية الأمريكية السيكولوجية المشار إليهـا

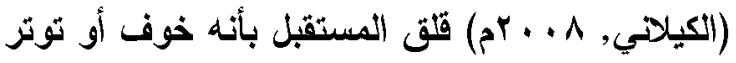
أو ضيق ينبع من توقع خطر ما يكون مصدره مجهولاً

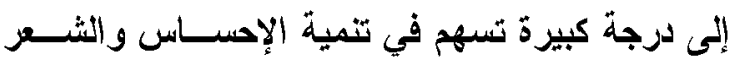

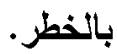
ويقصد به حالة من عدم الارتياح والتوتز والثــعرد بالضيق والخوف من مستقبل مجهول يتعلق بالعديــ هيد من جوانب الحياة (المحاميد و السفاسفة, V . . rم).

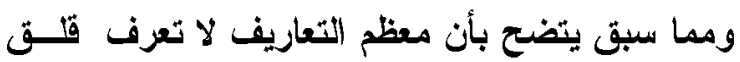

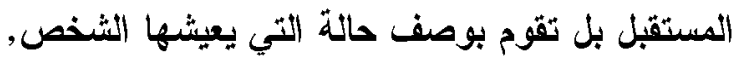

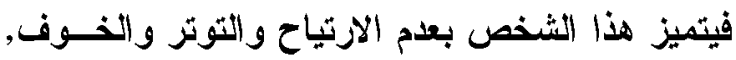
والتفكير السلبي اتجـاه المسـتقبل, يعشـر خلامهــا

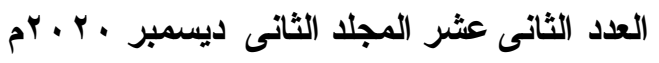

- أسباب بيزلوجية جسمية: أ- الأسباب الور اثية:

يعتبر العامل المراني هو أحد الأسباب التـي تســبب التباب

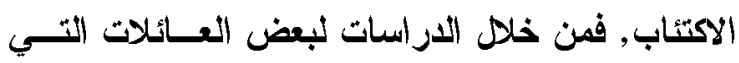

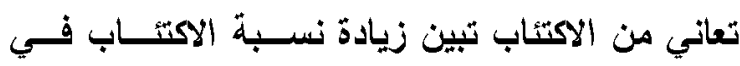

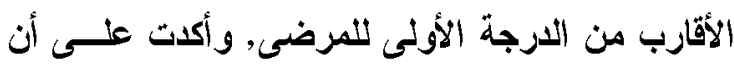

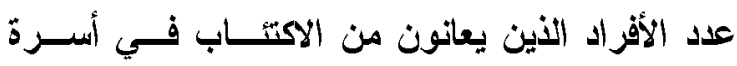

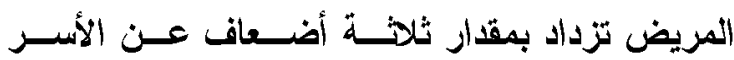

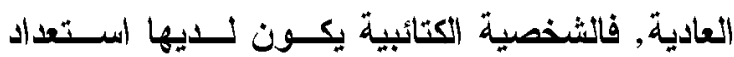

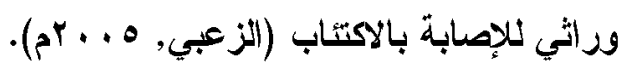
- أسباب عضوية كيميائية:

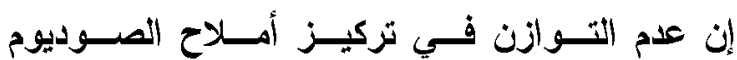
و البوتاسيوم في الجسم, بالإضافة للتغيرات التي تحثث

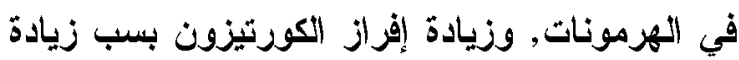
الثرمون المسؤول عن الغدة النخامية, والنقص في لئي إفراز الهرمون المنشط للغدة الارقية, الخلل في إفزراد

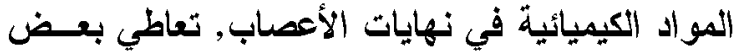

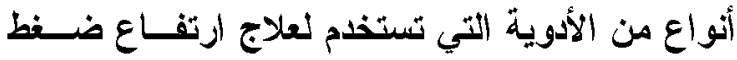

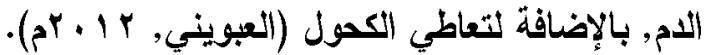
- أسباب نفسية واجتماعية:

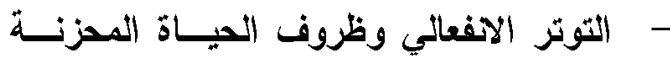
و الخبرات المؤلمة و الكوارث والاتهزام أمسام

\section{الثدائد.}

- الحرمان وفقا الحب والمســاندة العاطفيــة.

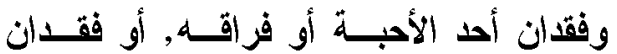
مصدر الدخل, أو فقدان المكانة الاجتماعية, فقدان الصحة. - الصر اعات اللاشعورية. - الإحباط و الفشـل وخيبـات الأهـلـل والكبـــ و والقلق. ضعف الأنا الأعلى واتهام الــات و الثــعور بالذنب الذي لا يغتفر بالنسبة لسلوك سابق.

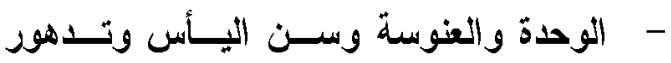
الكفاية الجنسية والشيخوخة والتقاعد. 
فالعزلة تعني ضعف العلاقات المتبادلــة بـين

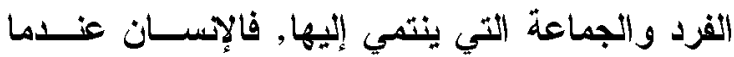

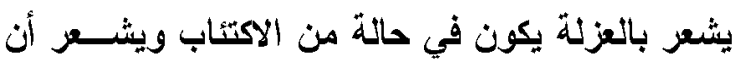
الههوم تثقله, مما يتزتب على هذا الإحساس أن ينفرد

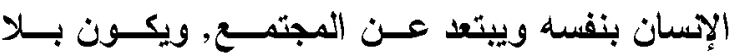

$$
\text { أصدقاء أو رفقة (غانم, r . . rم). }
$$

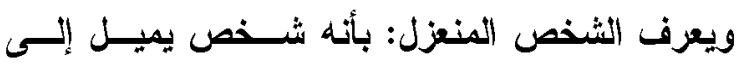

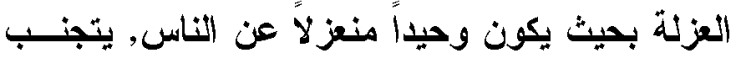

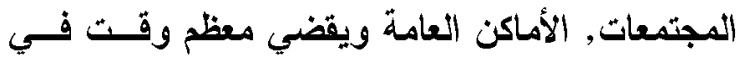

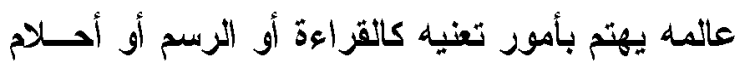
اليقظة, وإن كان بين جموع الناس يكون أغلب الوقت بهات صامتاً, وإن اضطر للكلام يكون في حالة من اضطر اب لئ

$$
\text { وخجل (قنيطة, r +. rم). }
$$

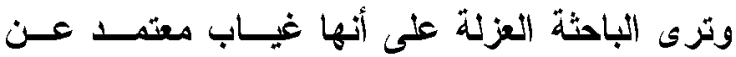

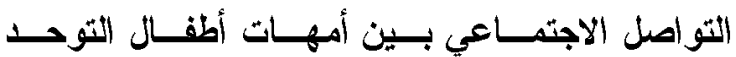

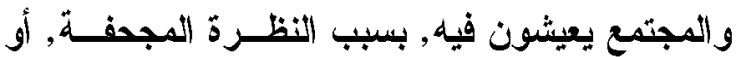
المشفقة التي يتلقونها من بعض أفزاد المجتمع. أسباب العزلة الاجتماعية:

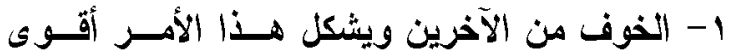

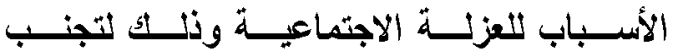
الاتجاهات السالبة والإحساس بالأذى الأي يكون مصدره الآخرين.

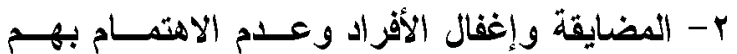

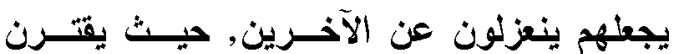
الانعز ال بحصول الألم.

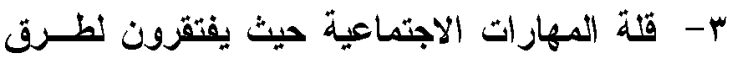
التو اصل مع الآخرين.

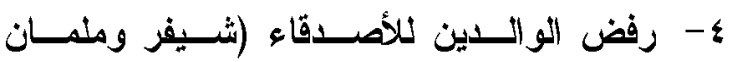

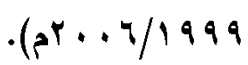

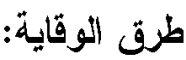

1- الانفتاح على الآخرين, حيث نجعل الأفــــاد

يتعرضون للخبرة الإيجابية, وأن يتم تحليـل

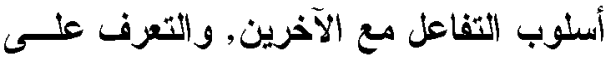
الأسباب التي تقودهم إلى المشاكل والاتعز ال.
الثخص بالخوف والتوتز والضـيق منبعـه مصــر

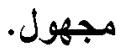

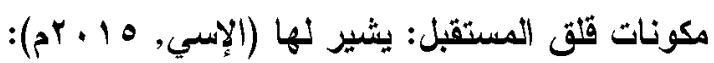

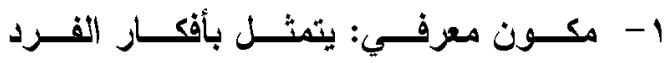

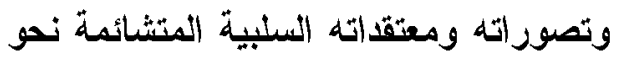

$$
\text { ما سيحدث في المستقبل. }
$$

r- المكون الانفعالي: يكون متمثـل باتفعـالات

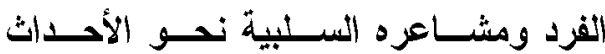
المستقبلية, وتكون ظاهرة على شكل خوف.

$$
\text { وقثق وتئز وقنوط وحزن. }
$$

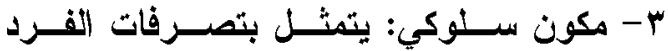

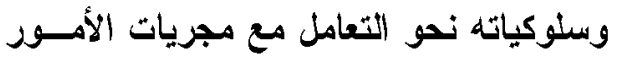

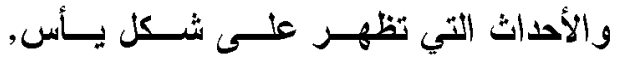

$$
\text { وتجنب, وحثر. }
$$

نالثاً: العزلة الاجتماعية

العزلة الاجتماعيـة تبعـد الثــص عـن العلاةــات الاجتماعية المفتوحة و الصريحة لفتــرة ظويلــة مــن

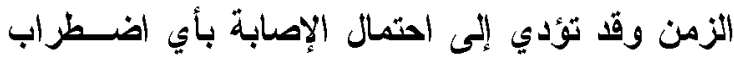

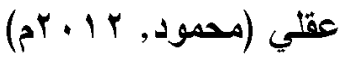

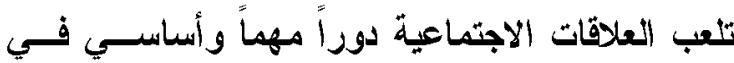
حياة البثرية, فهي مصدر للاعم والتوجيه للكثير من فن البثر , فانعلاثقات الاجتماعية تــوفر مصــراً للــعم

$$
\text { الاجتماعي. }
$$

تعزيف العزلة الاجتماعية: العزلة هي حالة من القطيعـة المحسدودة أو التامسـة التهية

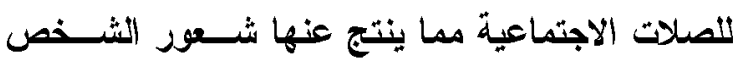
بالوحدة, وقا يكون الثخص هو المسؤول عن هـــه

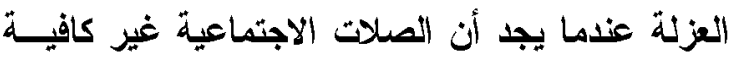

.(de jong Gierveld,2004)

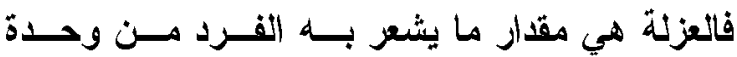

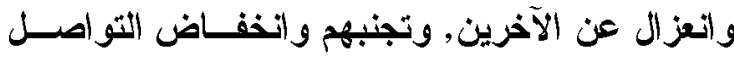

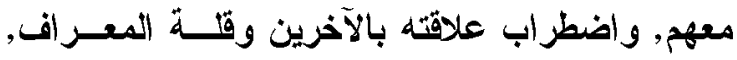
وعدم وجود أصدقاء مقزبين, وضعف شبكة العلاة واتـات الاجتماعية التي ينتمي إليها (عبد العال,r + . rم). 
الوصمة الاجتماعية لأمهات الأطفال ذوى الإعاقة مستاز عبد التكريم مدبولي حسبن

والأسباب, والنظريــات المفســرة, وطــرق الوقايــة و العلاج من هذه المثكلات. تعقيب عام على الإطار النظري: تناولت الاراسة الحالية الوصمة والمشئ المشكلات النفسـية والاجتماعية لأولياء أمور أطفال التزحد، حيث تعساني

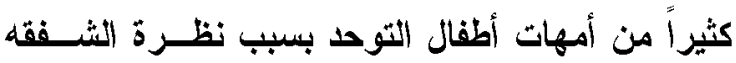
والعطف التي تلاحق طقلها وهذه النظرات تصيب الأم بالإحباط والقلق والاكتئاب, فهي تنظر لطفلها على أنه طفل مميز يتمتع بلرجة عالية من الأكاء, وتعثقل انه

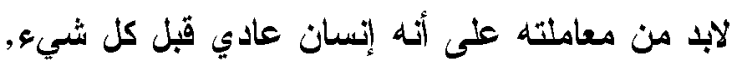

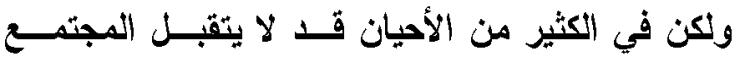

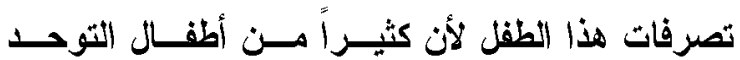
يتصرفون بعدوانية شديدة, ويبدأ المجتمع بإلقاء كثيراً

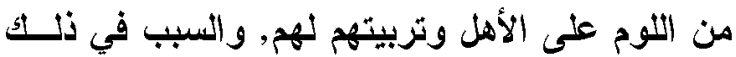

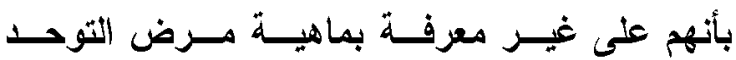

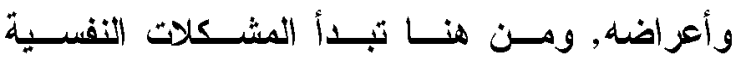
والاجتماعية بالظهور على أمهات أطفال التوح. وجود طقل توحدي فـــي الاســـرة يضـــــف الأعبــاء النفسية لأمهات أطفال التوحد, فتزيد حسدة الاكتئساب فهو اعتلال يعاني فيه الثخص من الحزن والمشاعر

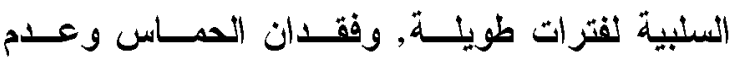
الاكتراث, ويصادفه مثاعر القلق والحزن والتثــاؤم والأنب ميح انعدام وجود هدف للحياة مما يجعل الفــرد يفتقد الواقع وتثعر بانعدام أي هدف للحياة.

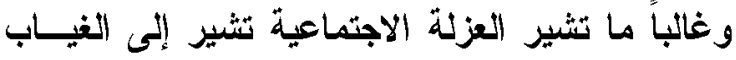

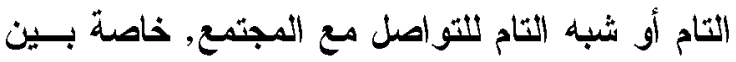

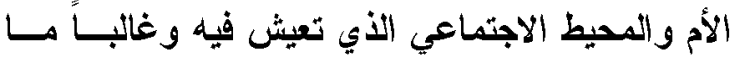

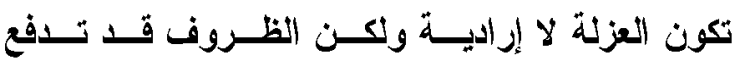

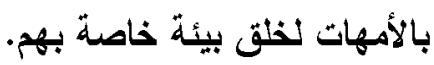

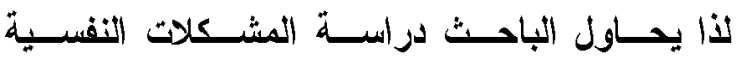
والاجتماعية لاى أمهات أطفال ذوي الإعاقــة خــلهل

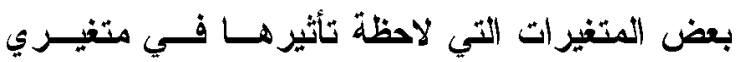
المشكلات النفسية والاجتماعية لاثى أمهــات أطفــال

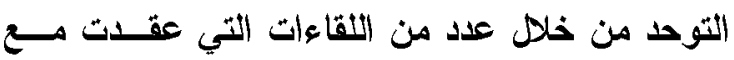
أمهات هؤلاء الأطفال.

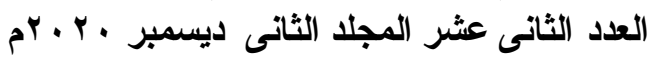

r- تعليم المنعزلين اجتماعياً الانتماء الإيجـابي

بواسطة النموذجة, السلوكيات الاجتماعيـة

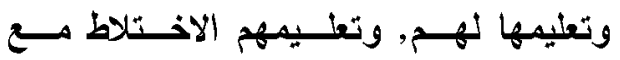
الآخرين وتجنب التزاع والمشاجرة, تقـــيم

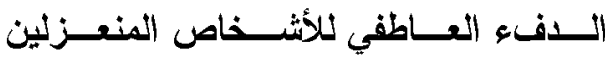
اجنماعياً.

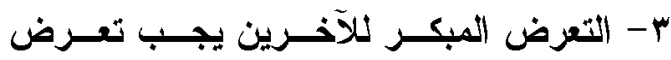

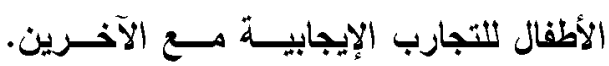

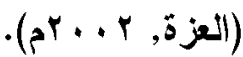

$$
\begin{aligned}
& \text { علاج العزلة الاجتماعية }
\end{aligned}
$$

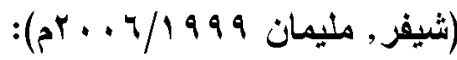

1- مكافئة أي شكل من التفاعل الاجتماعي يجب

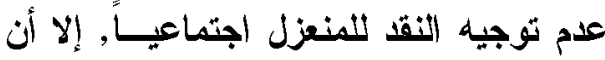

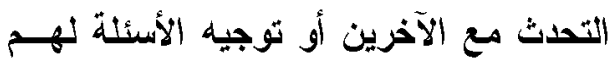

يجب أن يمتثح وأن يكافأ بشكل ملدوس. توجنه الاسنه r- تثجيع المشاركة مي الجماعة تثبيعاً نشطاً

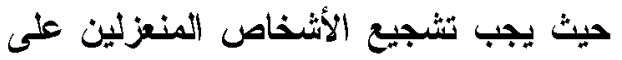
أن يكونا مي أثنخاص ثه شعبية اجتماعية,

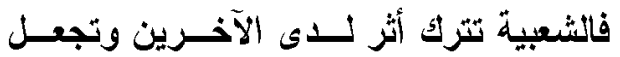
الثخص المنعزل أكثر تقبل من ثبل الآخرين.

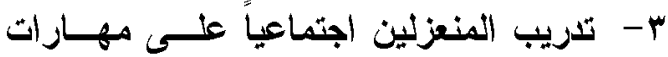
اجتماعية محدة أساسية.

تعليم مهارات الاتصال, خاصة كيفية الإصغاء. تعليمه كيف يقيم صداقات توجيه التحية ويسأل ويعطي الأهية معلومات ويقترح انتشر أك أنثخاص. ؟ - يبين كيف يعطي ويستقبل التفاعل الإيجابي.

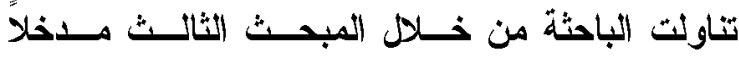

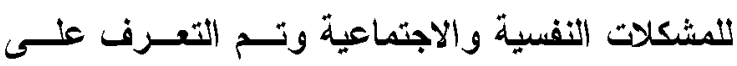

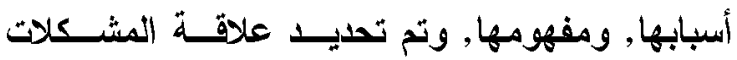

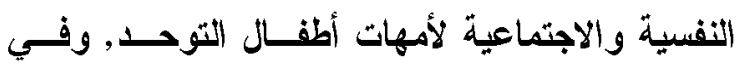

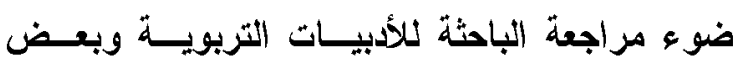

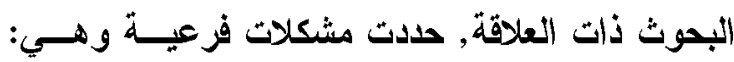

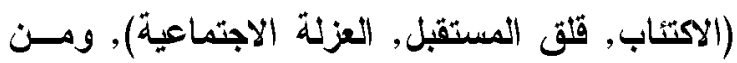

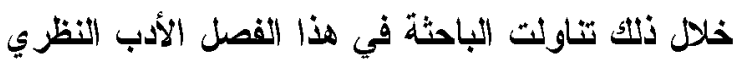

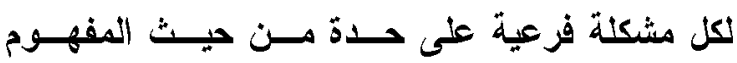


الوصـة الاجتماعية لأمهـات الأطفال ذوى الإعاقة مستاز عبد التكريم مدبولي حسبن

وأمهاتهم، مجلة أبحاث التربيـة الاساسـية جامعسة الموصل II (1)

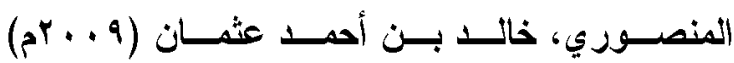
المشكلات الفنسية والاجتماعية الأكثر شييوعا وبعض لـن السمات الثخصية لدى عينة من طلبة كلية المعلمينين بجامعة الطائف (رسالة ماجستير غير منشورة) جامعة مئه أم القزى بمكة المكرمة، السعودية.

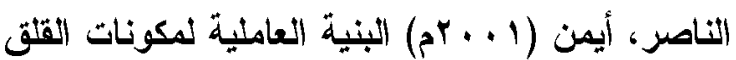
الاجتماعي لــثى عينـات مـن الثــباب المصــري و السعودي، مجلة علم التفسه V (1) . V.

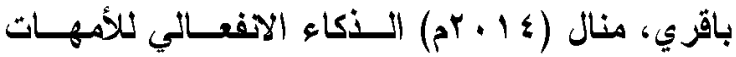
وعلاقته بالسلوك التكيفي لدىأطفال التوحد والــداون

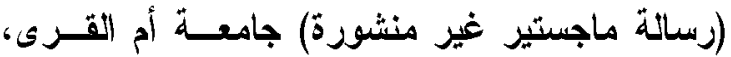

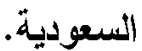

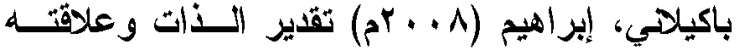
بالقلق المستقبل لدى الجالية العربية المقيمة بددينـة أوسلو في النرويج (رسالة ماجستير غير منشــورة)

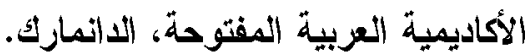

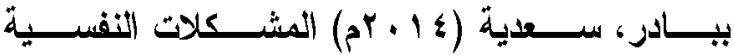
والاجتماعية الاكثر شيوعا لاى عينة من المــراهقين

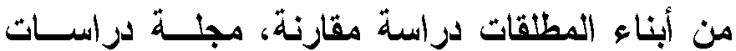

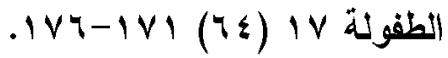

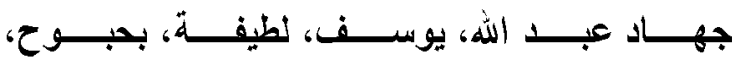
مالكا(11 +rام) علاج الاكتئاب الجسيم بطرق التعـديل

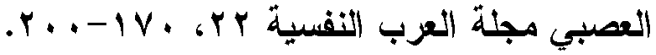

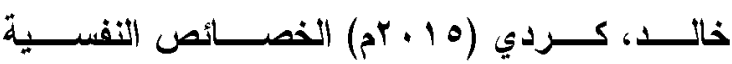

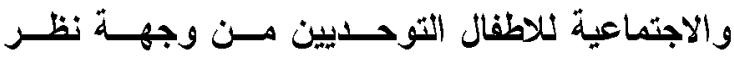
التو الائن، (رسالة ماجستير غيــر منشــورة) جامعسة

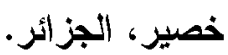

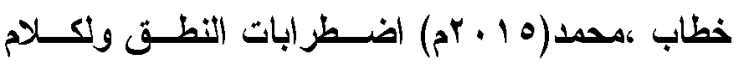

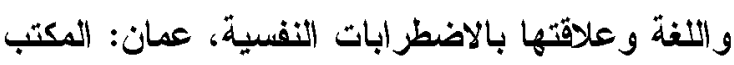
العربي للمعارف.

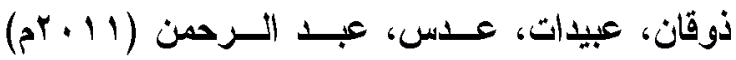
البحث العلمي ومفهومة وأدواتــه وأسـاليبه، الأردن عمان: دار الفكر. - مان

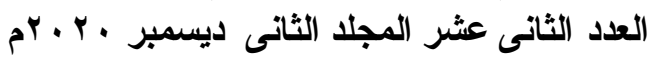

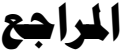

المراجع العربية

الخميسي، السيد (11 +rام) الضغوط الاسبـرية كمــابه يـركها آباء وأمهات الاطفال والمـر اهقين التوحسين

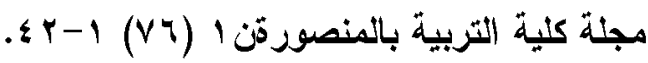

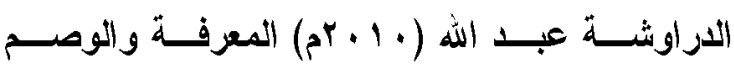

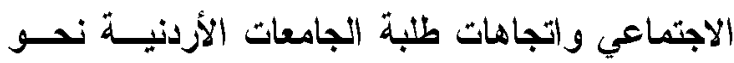

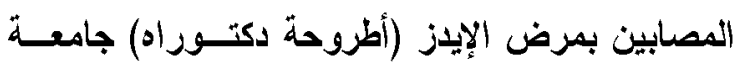
مؤتثة، الاردن.

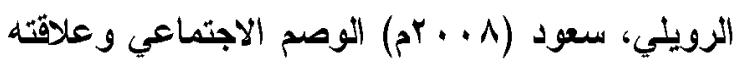

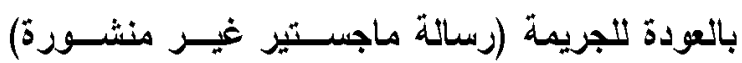
جامعة نايف للعظوم أمنية السعودية.

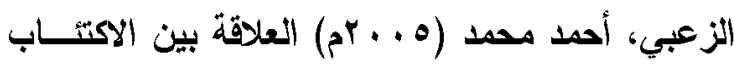

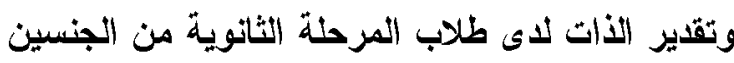

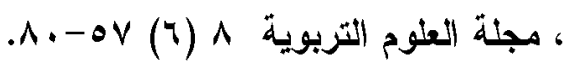

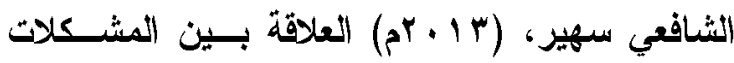

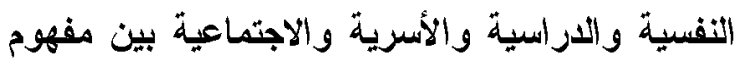

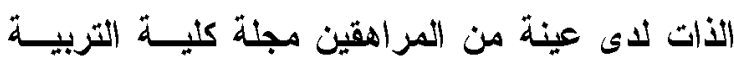

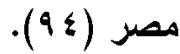

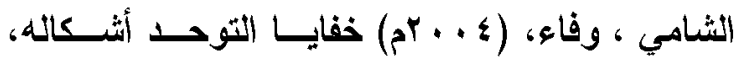

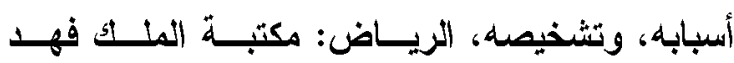

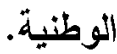

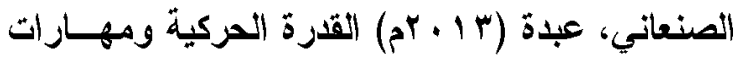
التواصل غير الفظي لدى أمهات أطفال التوحد، مجلة أنداه

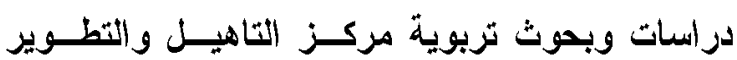

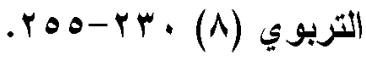

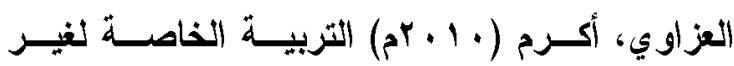
الاختصاص، عمان: دار الجنان للنشر والتوزيع.

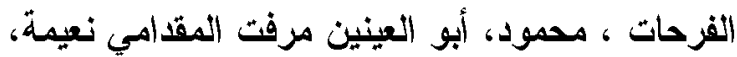

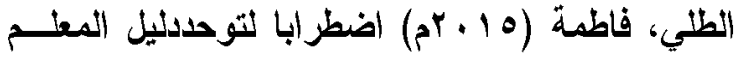

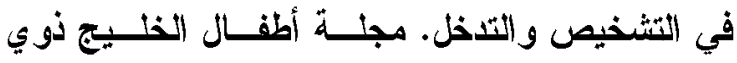
الاحتياجات الخاصة. الكيكي، محسن (11 +rم) المظاهر السلوكية لأطفــال التوحد في معهد الغست مسن وجهـــة نظـــر آبـائهم 
David, F. (2009). Exploring stigma medical knowledge and the stigmatization of parents of children diagnosed with autism spectrum disorder youth. Austalian: the university of melboume.

Editor, A. W.(2006). Autism current theories and evidence. Congress control.

Edward goldson, M. (2016). Advances in pediatrics Department of pediatrics. Children's hospital Colorado. USA. University of Colorado school of medicine.

Efrosini kalyva. (2011) . Autism, Sage publications Itd.

Faris, O.F. (2016). Stress, anxiety and depression among parents of children with autism spectrum disorder in oman: casestudies and evidence. (research published) Amman: sultan qaboos university. Goffiman, E. (1961). Asyluns: essays on the social situation of mental patients and other innates. Chicgo: Aldine.

Goffiman, E. (1963) stigma notes on the management of spoiled identity England; penguin group. Illness . (2011). Lessons for therapists and advocates. Wiley- Blackwel: chichester.

Juergus, S. (2012) History of Islamic medicine, vita medical.

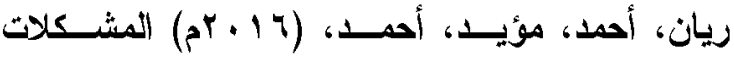

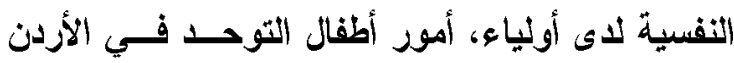
(رسالة ماجستير منشورة) جامعة الزرقاء، الأردن.

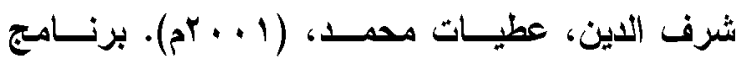

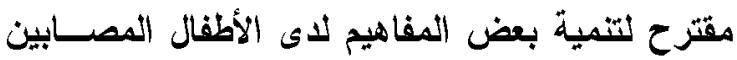

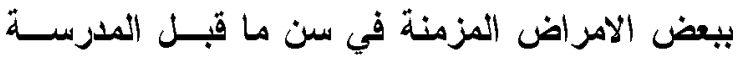

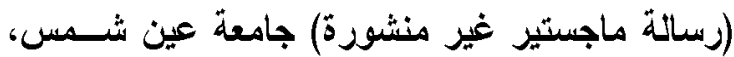
مصر

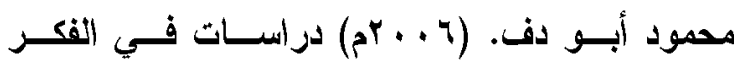
التزبوي الإسلاهي.

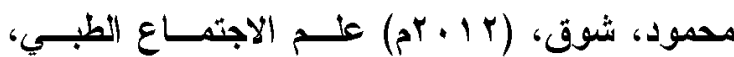
عمان: دار البداية. مصطفى، أسامة، الثربيني، كامل. (11 + آم) التوحد الأسباب - التشخيص - العلاج، عمان: دار المسـيرة لتلثر والتوزيع.

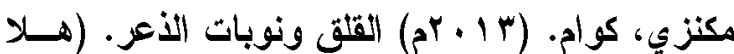
أمان الدين) الرياض: أصدرا دار المعارف.

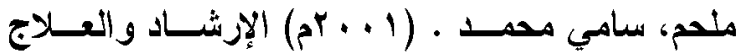
النفسي، عمان الأردن: دار الميسرة.

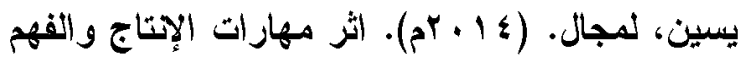

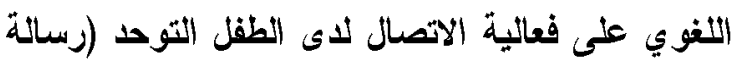

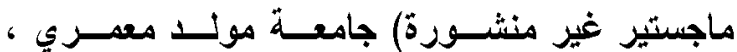

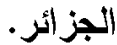

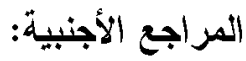
Baron- cohen, S. (2008). Autism and asperger syndrome. Oxford university press.

Belinda M. Keenan, L. K.()2016). Parents of children with ASD experience more psychological distress, parenting stress, and Attachmant- related anxiety. Autism and dievelopmental disorders, 2979-

2991. 
Parker, R. a. (2003). HIV and AIDSrelated stigma and discrimination: a conceptual framework and implications for action, social science and medicine.

Reber, A. (1986). Dictionary of psychology. Simulatan. Umberson D, M. J. (2015) , social relationships and health: a flashpoint for health policy. Health soc behave.

$51(54-6$. 